\title{
Article \\ KCNQ2 Selectivity Filter Mutations Cause Kv7.2 M-Current Dysfunction and Configuration Changes Manifesting as Epileptic Encephalopathies and Autistic Spectrum Disorders
}

\author{
Inn-Chi Lee ${ }^{1,2, *}$, Jiann-Jou Yang ${ }^{3}\left(\mathbb{D}\right.$, Ying-Ming Liou ${ }^{4,5}$ and Swee-Hee Wong ${ }^{3}$ \\ 1 Division and Pediatric Neurology, Department of Pediatrics, Chung Shan Medical University Hospital, \\ Taichung 40201, Taiwan \\ 2 Institute of Medicine, School of Medicine, Chung Shan Medical University, Taichung 40201, Taiwan \\ 3 Genetics Laboratory and Department of Biomedical Sciences, Chung Shan Medical University, \\ Taichung 40201, Taiwan; jiannjou@csmu.edu.tw (J.-J.Y.); a7710355@yahoo.com.tw (S.-H.W.) \\ 4 Department of Life Sciences, National Chung-Hsing University, Taichung 40227, Taiwan; \\ ymlion@dragon.nchu.edu.tw \\ 5 The iEGG and Animal Biotechnology Center, Rong Hsing Research Center for Translational Medicine, \\ Natinal Chung Hsing University, Taichung 40227, Taiwan \\ * Correspondence: y610@mercury.csmu.edu.tw
}

check for

updates

Citation: Lee, I.-C.; Yang, J.-J.; Liou, Y.-M.; Wong, S.-H. KCNQ2 Selectivity Filter Mutations Cause Kv7.2 M-Current Dysfunction and Configuration Changes Manifesting as Epileptic Encephalopathies and Autistic Spectrum Disorders. Cells 2022, 11, 894. https://doi.org/ $10.3390 /$ cells 11050894

Academic Editor: Anna Pannaccione

Received: 16 October 2021

Accepted: 1 March 2022

Published: 5 March 2022

Publisher's Note: MDPI stays neutral with regard to jurisdictional claims in published maps and institutional affiliations.

Copyright: (C) 2022 by the authors. Licensee MDPI, Basel, Switzerland. This article is an open access article distributed under the terms and conditions of the Creative Commons Attribution (CC BY) license (https:// creativecommons.org/licenses/by/ $4.0 /)$.

\begin{abstract}
KCNQ2 mutations can cause benign familial neonatal convulsions (BFNCs), epileptic encephalopathy (EE), and mild-to-profound neurodevelopmental disabilities. Mutations in the KCNQ2 selectivity filter (SF) are critical to neurodevelopmental outcomes. Three patients with neonatal EE carry de novo heterozygous KCNQ2 p.Thr287Ile, p.Gly281Glu and p.Pro285Thr, and all are followed-up in our clinics. Whole-cell patch-clamp analysis with transfected mutations was performed. The Kv7.2 in three mutations demonstrated significant current changes in the homomerictransfected cells. The conduction curves for $\mathrm{V}_{1 / 2}$, the $\mathrm{K}$ slope, and currents in 3 mutations were lower than those for the wild type (WT). The p.Gly281Glu had a worse conductance than the p.Thr287Ile and p.Pro285Thr, the patient compatible with p.Gly281Glu had a worse clinical outcome than patients with p.Thr287Ile and p.Pro285Thr. The p.Gly281Glu had more amino acid weight changes than the p.Gly281Glu and p.Pro285Thr. Among 5 BFNCs and 23 EE from mutations in the SF, the greater weight of the mutated protein compared with that of the WT was presumed to cause an obstacle to pore size, which is one of the most important factors in the phenotype and outcome. For the 35 mutations in the SF domain, using changes in amino acid weight between the WT and the KCNQ2 mutations to predict EE resulted in $80.0 \%$ sensitivity and $80 \%$ specificity, a positive prediction rate of $96.0 \%$, and a negative prediction rate of $40.0 \%\left(p=0.006, \chi^{2}(1, n=35)=7.56\right.$; odds ratio 16.0, $95 \%$ confidence interval, 1.50 to 170.63$)$. The findings suggest that p.Thr287Ile, p.Gly281Glu and p.Pro285Thr are pathogenic to KCNQ2 EE. In mutations in SF, a mutated protein heavier than the WT is a factor in the Kv7.2 current and outcome.
\end{abstract}

Keywords: whole-cell patch-clamp analysis; ASD; epileptic encephalopathy; children; KCNQ2

\section{Introduction}

KCNQ2 (OMIM 602235)-associated seizures typically occur in the first week from birth and can contribute to benign familial neonatal convulsions (BFNCs), benign familial infantile seizures [1-5], and neonatal-onset epileptic encephalopathy (EE) [6-8]. KCNQ2 BFNCs are generally predicted to follow a benign course and are expected to have unremarkable outcomes. The majority of neonatal-onset EE mutations are de novo; they are rarely mosaic. Patients with $K C N Q 2$ EE present with severe seizures that often remit as patients become older; however, such patients experience poor neurodevelopmental outcomes in terms of cognition, motor skills, and language, and they may also exhibit autistic spectrum disorder (ASD). This condition is called developmental EE [9,10]. 
Neurodevelopmental outcomes can be determined by genotype; the related functional consequences result from mutations caused by M-current changes, prolonged seizure duration, and environmental factors. Among these factors, genotype is the most critical in determining outcomes [11-14].

KCNQ channels, which include a voltage sensor in S1-S4 and S5-S6 as well as a loop between S5 and S6 that creates an ion channel pore, a cytoplasmic N-terminal, and a long C-terminal region with complex functions in interactions among syntaxin, phosphatidylinositol 4, 5-bisphosphate, ankyrin-G, Syn-1A, and A-kinase anchoring proteins [2,5,15-20]. The S5 and S6 segments, along with an intervening reentrant loop (P-loop domain), form the pore region. Mechanisms that govern the expression of Kv7.2 include the network of interactions of the pore region with the selectivity filter (SF) and the S6, which are responsible for the Kv7.2 current and control of the KCNQ2 protein on the plasma membrane by the C-terminus distal part for channel trafficking and assembly. The C-terminus includes two helical domains (helices A and B) for channel modulation through interaction with calmodulin [21,22]. Helix A contains the consensus CaM-binding IQ motif, and helix B mediates $\mathrm{Ca}^{2+}$-dependent CaM binding [23]. All KCNQ channel members have large C-termini that may form "receptorsomes" or "channelosomes" for incorporation with multiple signaling pathways [24]. Mutations in the KCNQ2 gene can cause haploinsufficiency and a severe dominant-negative effect due to a loss of function and gain of function. Loss of function explains the majority of cases of neonatal-onset EE [25-28], but a gain in function is presumed to be the mechanism behind several mutations [25,28-32]. The mutations located on the SF of the pore domain significantly impact the Kv7.2 and cause severe functional consequences. The SF located between S5 and S6 is highly conserved and controls $\mathrm{K}^{+}$permeability and selectivity [33-37]. The SF is critical for maintaining $\mathrm{K}^{+}$permeability and selectivity; its amino acid position in KCNQ2 is from protein 253 to 291.

KCNQ2 EE mostly manifests as ASD and poor neurodevelopmental behaviors such as language delay, stereotypical behavior, and seizures. In patients with KCNQ2-related BFNC, the reported neurodevelopmental outcomes are healthy neurodevelopment, mild intellectual disability, and attention deficit disorder. In one case, KCNQ2 EE caused hyperkinetic movement of the limbs beyond age 4 weeks [38]. Neonatal seizures associated with severe neonatal myoclonus such as dyskinesia due to a familial KCNQ2 gene mutation was reported [39]. However, the manifestations beyond neonatal age was rarely reported.

The SF in KCNQ2 is from protein 253 to 291 (Figure 1). We found 35 mutations [5 caused BFNCs $(14.3 \%)$ and 30 caused EE $(85.7 \%)]$ according to a comprehensive literature review of the literature. All neurodevelopmental outcomes related to BFNCs were favorable. Among patients with mutations causing EE, the outcomes were poorer than the outcomes of those with mutations causing BFNCs and varied from moderate or severe to profound developmental disabilities and early mortality.

The precise genotype-phenotype correlation in KCNQ2-related epilepsy is not fully understood. We demonstrated that patients with KCNQ2 EE exhibited dyskinetic movement disorders and ASD after infantile age and determined that three KCNQ2 variants in the SF of the pore domain caused functional current changes in HEK293 cells. Second, to predict the consequences of mutated proteins in the KCNQ2 SF, we hypothesized that mutations correlated with phenotype and neurodevelopmental outcomes were also correlated with changes in the mutated protein of the SF. We analyzed various mutations in the SF to predict structural changes at the molecular level. 


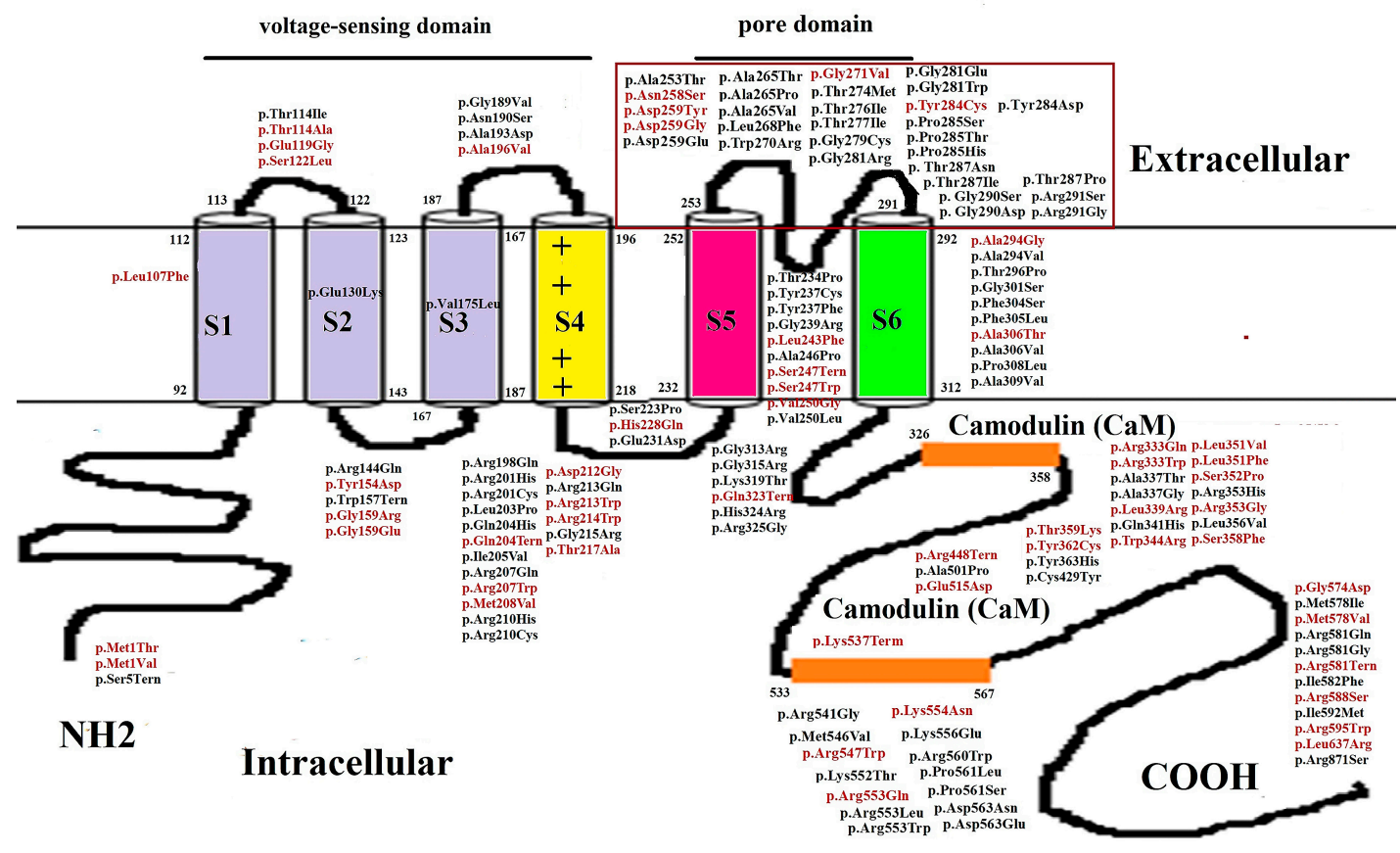

Figure 1. Mutations of $K C N Q 2$ are demonstrated in corresponding to $K C N Q 2$ functional domains. Mutations with red fonts indicate the phenotype of BFNCs; mutations with black fonts are KCNQ2 EE. Twenty-eight mutations (within the brown square) are in the SF domain of KCNQ2. Five mutations highlighted in red $(17.9 \%)$ indicate those causing benign familial neonatal convulsions; 23 mutations highlighted in black $(82.1 \%)$ indicate those causing epileptic encephalopathy.

\section{Materials}

Participants

Two hundred twenty-six patients were enrolled from 2015-2020, and met the criteria for "childhood epilepsy without an identified cause" ([1] age of first seizure less than 18 years old and [2] at least one magnetic resonance image (MRI) with no detectable seizure-related lesions) after excluding patients with the obvious MRI findings indicating lesional epilepsies. Ten (4.4\%) patients ( 5 boys; 5 girls) had KCNQ2 mutations: one each for c.860 C > T (p.Thr287lle); c.740 C > T (p.Ser247Leu); c.842G > A (p.Gly281Glu); c.853 C > A (p.Pro285Thr); c.1294 C > T (p.Arg432Cys); c.1342C > T (Arg448Ter); c.1627 G > A (p.Val543Met); c.1741 C > T (p.Arg581Ter) and a splicing mutation: c.387 + $1 \mathrm{G}>\mathrm{T}$. The $K C N Q 2$ sequencing data were compared with the GenBank reference sequences and the version numbers of the KCNQ2 gene (NM_172107.3).

Three $(30 \%)$ out of ten mutations located in the SF of the KCNQ2 protein were p.Thr287Ile, p.Gly281Glu and p.Pro285Thr mutations, and presented with neonatal-onset EE, movement disorders and ASD. We transfected these variants (p.Thr287lle, p.Gly281Glu and p.Pro285Thr) into HEK293 cells to investigate Kv7.2 current changes and the KCNQ2 protein expression in HEK293 cell membranes.

\section{Methods}

\subsection{Computational Protein Analysis of SF Mutations and Their Phenotypes}

A molecular model of KCNQ2 channel proteins (NM_004518) was generated using the Phyre2 tool (Protein Homology/analogY Recognition Engine V 2.0, Imperial College, London) and the NP_004509.2 protein sequence. This tool can be used to conduct protein modeling, prediction, and analysis based on the CryoEM structure of the Xenopus KCNQ1 channel [40]. The predicted 3D model of the KCNQ2 channel protein (c5vmsA_.1.pdb) was then used along with SPDBV and PyMOL to analyze the structural differences between wild type (WT) and mutant cells. The 3D structure was predicted through homology modeling using the Phyre2 database and was validated using SPDBV. Common characteristics of 
the predicted protein, such as molecular weight, isoelectric point, amino acid composition, and the aliphatic and instability indexes, were assessed using the ProtParam tool. We used the Human Gene Mutation Database (HGMD) (http:/ / www.hgmd.cf.ac.uk/ac/index. php, accessed on March 2021) and National Center for Biotechnology Information (NCBI) ClinVar (https: / / www.ncbi.nlm.nih.gov/clinvar, accessed on March 2021) database to assess SF mutations in the pore domain. The WT and mutated protein characteristics were then analyzed.

\subsection{Mutations of KCNQ2 in Corresponding to KCNQ2 Functional Domains and Phenotypes}

We reviewed the database in HGMD and NCBI and confirmed the pathogenic characters of the mutations to review the corresponding literatures. We collected the missense mutations of KCNQ2. The phenotypes were classified to BFNC and KCNQ2 EE.

\subsection{Expression in HEK293 Cells}

HEK293 cells were maintained in Dulbecco's modified Eagle's medium (DMEM) (Biowhittaker, Walkersville, MD, USA) supplemented with 10\% fetal bovine serum (FBS), penicillin $(100 \mathrm{U} / \mathrm{mL})$, streptomycin $(100 \mathrm{U} / \mathrm{mL})$, and $2 \mathrm{mM}$ L-glutamine (Lonza, Walkersville, MD, USA). Mutations in KCNQ2 were induced using a kit (QuickChange; Stratagene, La Jolla, CA, USA) and verified using sequencing [41].

\subsection{Transfecting Variants to HEK293 Cells}

HEK293 cell cultures were maintained at $37{ }^{\circ} \mathrm{C}$ in a humidified $5 \% \mathrm{CO}_{2}$ incubator. The vectors pLEGFP and pTaqRFP, which contained DNA fragments encoding both wild-type and mutant KCNQ2, were transfected to HEK293 cells using a reagent (lipofectamine; Thermo Fisher Scientific: Invitrogen, Carlsbad, CA, USA). KCNQ2 mutations were induced using a kit (QuickChange; Stratagene, La Jolla, CA, USA) and verified using sequencing. KCNQ2 WT and mutant KCNQ2 alleles were transfected into HEK293 cells in homomeric mutants $(2 \mu \mathrm{g})$ and heteromeric KCNQ2+ mutants $(1 \mu \mathrm{g}+1 \mu \mathrm{g})$, respectively. After transfection with heteromeric KCNQ2 WT and its variants and WT KCNQ3 (0.5 $\mu \mathrm{g}: 0.5 \mu \mathrm{g}: 1 \mu \mathrm{g})$, the DNA ratio mimicked the genetic balance.

\subsection{Whole-Cell Patch-Clamp Analysis}

For electrophysiological analysis, HEK293 cells were washed in modified Tyrode's solution containing $125 \mathrm{mM} \mathrm{NaCl}, 5.4 \mathrm{mM} \mathrm{KCl}, 1.8 \mathrm{mM} \mathrm{CaCl}_{2}, 1 \mathrm{mM} \mathrm{MgCl}, 6 \mathrm{mM}$ glucose, and $6 \mathrm{mM}$ HEPES ( $\mathrm{pH}$ 7.4). Patch pipettes had a resistance of 3-4 $\Omega$ when filled with a solution containing $125 \mathrm{mM}$ potassium gluconate, $10 \mathrm{mM} \mathrm{KCl}, 5 \mathrm{mM} \mathrm{HEPES}, 5 \mathrm{mM}$ EGTA, $2 \mathrm{mM} \mathrm{MgC}_{12}, 0.6 \mathrm{mM} \mathrm{CaCl}_{2}$, and $4 \mathrm{mM}$ adenosine $5^{\prime}$-triphosphate disodium salt hydrate (Na2ATP; pH 7.2). KCNQ2 mutations were created using a QuickChange kit (Stratagene, La Jolla, CA, USA) and verified through sequencing [41]. To measure the voltage dependence of activation, the cells were clamped using 3-s conditioning voltage pulses to potentials between $-80 \mathrm{mV}$ and $+40 \mathrm{mV}$ in $10-\mathrm{mV}$ increments from a holding potential of $-80 \mathrm{mV}$. Data acquisition and analysis were using analysis software (Clampex 10.0; Molecular Devices, Sunnyvale, CA, USA). The data were then fitted to a Boltzmann distribution of the following form: $G / G \max =1 /\left(1+\exp \left[\left(V-V \frac{1}{2}\right) / d x\right]\right)$. Cell capacitance was obtained by reading the settings for the whole-cell input capacitance neutralization directly from the amplifier [42]. KCNQ2 mutation variants and KCNQ2 WT were transfected into HEK293 cells to determine the functional changes resulting in conductance-current curve changes $[14,43]$.

\subsection{Cytoplasmic and Membranous Protein Separation}

Three wells were covered with HEK293 cells $\left(6 \times 10^{6}\right)$ in a $10-\mathrm{cm}$ cell culture dish. The cells were washed two or three times with phosphate buffered saline (PBS) containing $4 \mathrm{~g}$ of $\mathrm{NaCl}, 0.1 \mathrm{~g}$ of $\mathrm{KCl}, 0.72 \mathrm{~g}$ of $\mathrm{Na}_{2} \mathrm{HPO}_{4}, 0.13 \mathrm{~g}$ of $\mathrm{KH}_{2} \mathrm{PO}_{4}$, with an adjusted $\mathrm{pH}$ of 7.4. The cells were then added to wells containing sucrose in a homogeneous solution $(40 \mathrm{mM}$ 
of Tris- $\mathrm{HCl}[\mathrm{pH}=7.4], 0.34 \mathrm{M}$ sucrose, $10 \mathrm{mM}$ EDTA, $\left.1 \mathrm{mM} \mathrm{MgSO}_{4}\right)$, and where $1 \mathrm{~mL}$ of 1-mM phenylmethyl sulfonyl fluoride (PMSF) was then added. The cell mixture was placed on ice and sonicated three times for 2 min each (intensity: 30). It was then slowly added to a mixture of $1.5 \mathrm{~mL}$ of $50 \%$ sucrose in a centrifuge tube $(40 \mathrm{mM}$ Tris- $\mathrm{HCl}$ [pH 7.4], $50 \%$ sucrose, $10 \mathrm{mM}$ ethylenediaminetetraacetic acid (EDTA), $1 \mathrm{mM} \mathrm{MgSO}_{4}, 2 \mathrm{mM} \mathrm{NaN}_{4}$ ) and $0.75 \mathrm{~mL}$ of $20 \%$ sucrose ( $40 \mathrm{mM}$ of Tris- $\mathrm{HCl}$ [pH 7.4], $20 \%$ sucrose, $10 \mathrm{mM}$ EDTA, $1 \mathrm{mM}$ $\mathrm{MgSO}_{4}, 2 \mathrm{mM} \mathrm{NaN}_{4}$ ), and completely shook cell homogeneously. The solution was then centrifuged in an ultra-high-speed rotor (55-Ti; Beckman Coulter Taiwan, Taipei) at $4{ }^{\circ} \mathrm{C}$ and $26,200 \mathrm{rpm}$ for $90 \mathrm{~min}$. After the solution had been centrifuged, the cellular proteins rose to the top of the liquid.

\subsection{Western Blotting}

Samples were diluted to at least 1:5 with sample buffer, heated at $95{ }^{\circ} \mathrm{C}$ for $5 \mathrm{~min}$, and then stored at $4{ }^{\circ} \mathrm{C}$ until use. The gel was run at $80 \mathrm{~V}$ for $10 \mathrm{~min}$ and then at $130 \mathrm{~V}$ for $3 \mathrm{~h}$. To prepare for Western blotting, the polyvinylidene difluoride (PVDF) membrane (Millipore) was soaked in methanol for $1 \mathrm{~min}$ and then placed in the "sandwich" chamber with 2 fiber pads and 2 filter papers that absorbed the old transfer buffer. The "sandwich" was transferred for $1.5 \mathrm{~h}$ at $100 \mathrm{~V}$ at $4{ }^{\circ} \mathrm{C}$. The membrane was then shaken in $5 \%$ nonfat dry milk in PBS for $1 \mathrm{~h}$ in a shaker at room temperature; it was then incubated overnight with a primary anti-KCNQ2 antibody (1:200; Thermo Fisher) in $1 \%$ milk at $4{ }^{\circ} \mathrm{C}$ in a shaker. The next day, after it had been washed with PBST (phosphate buffer saline + Tween20) four times for 10 min each time, the membrane was incubated with a secondary antibody (antirabbit) (1:3000; Gentex) in 1\% milk prepared with PBS for approximately $1 \mathrm{~h}$ at room temperature. It was then rinsed with PBST four times for 10 min each time and analyzed using a Western blotting detection kit (Advansta, Menlo Park, CA, USA). An anti-GAPDH antibody was used as the internal control and anti-pan cadherin was used as a cell membrane marker.

\subsection{Ethics}

The Chung Shan Medical University Hospital's Institutional Review Board provided the ethical approval for the study (IRB \#: CS2-14003). Written informed consents were obtained from parents of all three patients.

\subsection{Statistics}

Significant differences between groups were evaluated using an independent $t$ test to compare wild types and mutants. The chi-squared test was used to differentiate categorical variables, and the Fisher exact test was used when sample sizes were small. The odds ratio $(\mathrm{OR})$ was calculated by dividing the odds of the first group by the odds of the second group, and OR represents the association between a variable and an outcome. Significance was set at $p<0.05$. The exact $p$ values are expressed, unless $p$ is $<0.001$. All statistical tests were carried out using SPSS (version 14.0; SPSS Institute, Chicago, IL, USA).

\section{Results}

Three patients with mutations in SF presented as KCNQ2 EE and ASD. To determine that three KCNQ2 variants in the SF cause functional current changes in HEK293 cells and to predict the consequences of mutated proteins in the KCNQ2 SF, we analyzed the functional currents in the mutations in the SF, and predicted the structural changes at the molecular level by computational protein analysis.

\subsection{Clinical Presentations in 3 Patients with KCNQ2 Mutations in SF Domain}

Patient 1 carried de novo p.Thr287Ile (uncertain significance according to NCBI ClinVar databases) and presented with neonatal seizures since day 3 of life. He first received intravenous phenobarbital, which could not control his seizures. The addition of oxcarbazepine (OXC) and topiramate controlled his seizures. After 3 months, he was prescribed OXC and topiramate for seizure control. He could not walk, and he had a severe cognitive 
disability without development of any language at 3 years old. After age 3 years, his parents found that he had repeated dyskinetic movements while awakening. The stereotyped episodes could occur up to 30 times during night and day without external stimulation. Related movements could also occur when the patient played with his parents. Antiepileptic drugs such as levetiracetam and topiramate did not affect these movements. An electroencephalogram (EEG) monitor showed no paroxysmal activity when the movements occurred, proving that it was not a seizure (Table 1).

Table 1. Clinical presentations and long-term neurodevelopmental outcomes in three KCNQ2 mutations located in SF domain.

\begin{tabular}{|c|c|c|c|}
\hline & Patient 1 & Patient 2 & Patient 3 \\
\hline Genotype in patients & p.Thr287Ile & p.Gly281Glu & p.Pro285Thr \\
\hline Inheritance & De novo & De novo & De novo \\
\hline Functional domain & Selectivity filter & Selectivity filter & Selectivity filter \\
\hline Family history & No & No & No \\
\hline First seizure day & Day 3 & Day 3 & Day 2 \\
\hline $\begin{array}{l}\text { Seizure frequency before } \\
\text { drug control }\end{array}$ & Daily & Daily & Daily \\
\hline Age when seizure-free & $\begin{array}{c}\text { Partial remission of seizures at } \\
4 \text { months, with recurrent } \\
\text { febrile seizures }\end{array}$ & No remission of seizures & $\begin{array}{c}\text { Partial remission of seizures } \\
\text { after } 1 \text { year }\end{array}$ \\
\hline MRI & Unremarkable at 4 years old & $\begin{array}{l}\text { Thin corpus callosum, brain } \\
\text { atrophy at } 4 \text { years old }\end{array}$ & Thin corpus callosum \\
\hline $\begin{array}{c}\text { Long-term } \\
\text { neurodevelopmental } \\
\text { outcomes }\end{array}$ & $\begin{array}{l}\text { Lack of language production, } \\
\text { can sit, inability to walk, } \\
\text { severe cognitive disability at } \\
5 \text { years old. }\end{array}$ & $\begin{array}{l}\text { Lack of language production, } \\
\text { cannot sit without support, } \\
\text { inability to walk, severe } \\
\text { cognitive disability at } \\
5 \text { years old. }\end{array}$ & $\begin{array}{c}\text { Lack of language, can sit, } \\
\text { inability to walk, severe } \\
\text { cognitive disability at } \\
4 \text { years old. }\end{array}$ \\
\hline
\end{tabular}

The sequence data of each patient were checked against the GenBank reference sequence and version number of KCNQ2 gene (NM_172107.3). MRI, magnetic resonance imaging.

Patient 2 was aged 4 years and carried a de novo p.Gly281Glu mutation (likely pathogenic according to NCBI ClinVar). She presented with seizures since day 2 of life, and her condition was not responsive to intravenous phenobarbital and phenytoin. $\mathrm{Nu}$ merous drugs were administered, including oxycarbamazepine ( $30 \mathrm{mg} / \mathrm{kg}$ /day). During the period of ictal seizures, the patient exhibited stereotypical right-hand tonic seizures during both sleeping and waking states. The seizures occurred up to five times per day. The ictal EEGs revealed rhythmic delta waves in the left hemisphere and were associated with right-hand tonic movements. At age 4 years, the patient had spontaneous hyperkinetic behavior without external stimulation and still had seizures on a weekly basis (Table 1).

Patient 3 with the de novo p.Pro285Thr mutation, had frequent neonatal seizures, and apnea. Her EEG showed burst-suppression. She had neonatal seizures and was treated with multiple antiepileptic drugs. The seizures abated 2 months after she had been treated with oxcarbazepine. The seizures became less frequent after she turned 2 months old, but she had a severe cognitive disability and no language development at 4 years of age (Table 1).

\subsection{Electrophysiological Properties of p.Thr287Ile in KCNQ2 Mutations}

We analyzed the variant (p.Thr287Ile) in which the cell M-current was affected after the transfection of homomeric and heteromeric variants (Figure $2 \mathrm{~A}(\mathrm{a}-\mathrm{c})$ and Table 2). In HEK293 homomeric-transfected variants, the p.Thr287lle cells expressed significantly lower currents (Supplementary Table S1) than did the KCNQ2 WT when they were transfected with KCNQ2 (Figure 2A(d)); a normalized current was significantly lower in homomeric p.Thr287Ile after -30 to $-20 \mathrm{mV}$ and $0 \mathrm{mV}$ episodes of conditional stimulation in HEK293 cells (Figure 2A(e)). The homomeric currents were lower in p.Thr287lle $(481.8 \pm 56.9 \mathrm{mV} ; n=10)$ than the currents in the KCNQ2 WT $(579.8 \pm 46.0 \mathrm{mV} ; n=22)$ (Table 2 and Figure 2A(d)). The conduction curves for $\mathrm{V}_{1 / 2}$ is right shifting $4.7 \mathrm{mV}$ 
$(-12.2 \pm 1.9 \mathrm{mV}$ in homomeric p.Thr287lle versus $-16.9 \pm 2.0 \mathrm{mV}$ in KCNQ2 WT), and $\mathrm{K}$ (slope) $[8.3 \pm 1.3$ (mV/e-fold) in homomeric p.Thr287lle versus $9.5 \pm 2.2(\mathrm{mV} / \mathrm{e}$-fold) in KCNQ2 WT] were lower than those for the WT (Table 2). The conduction curve exhibited a significant impairment in the homomeric p.Thr287Ile channel.
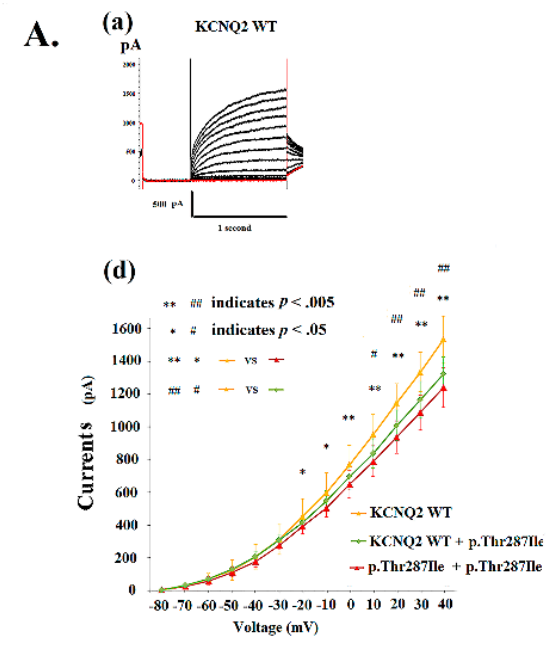

B. (a)

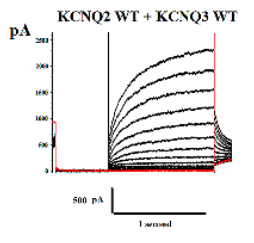

(c)

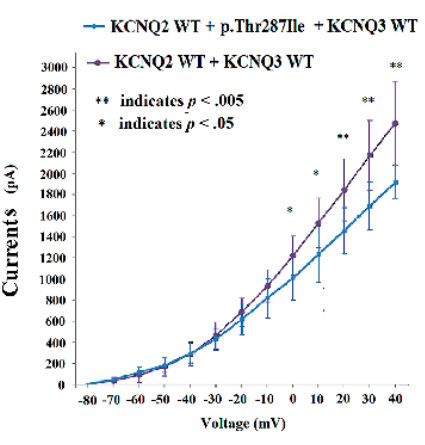

C.

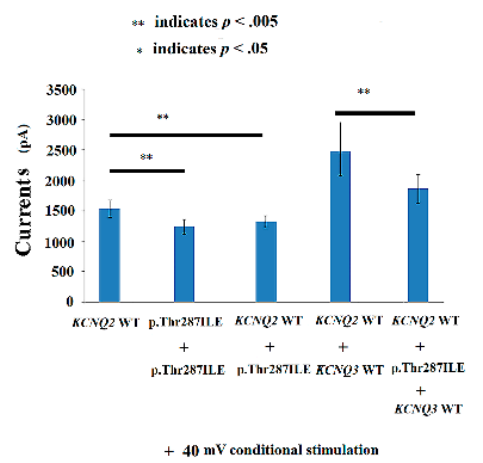

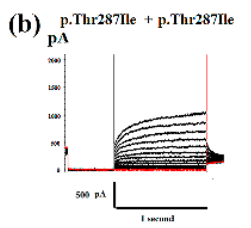

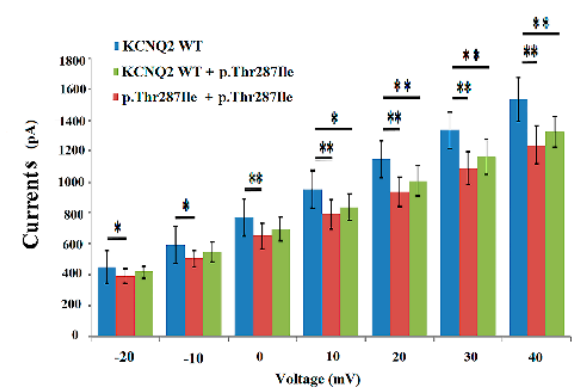

(b)
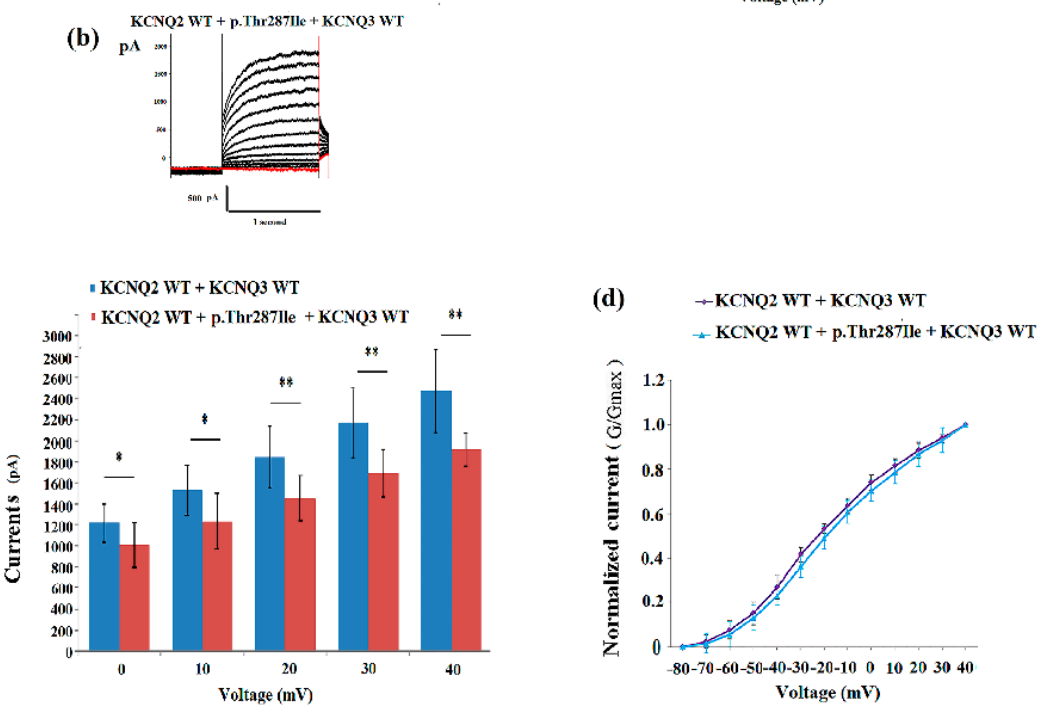

(b)

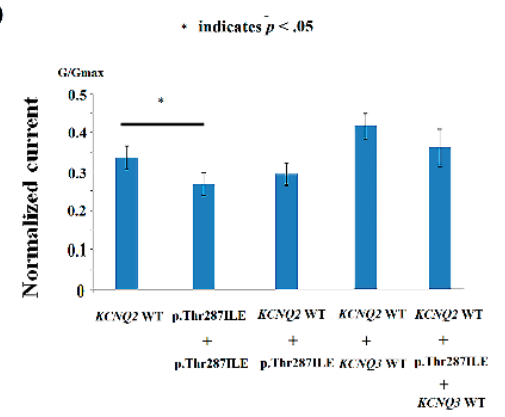

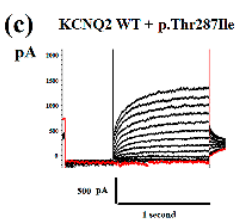

(e)

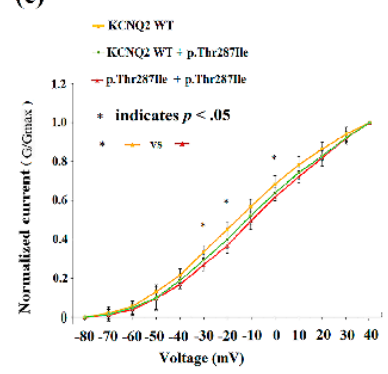

Voltage $(\mathbf{m V})$

Figure 2. (A) Analysis of the electrophysiological properties of HEK293 cells in KCNQ2 channels. The voltage-clamp steps were from $-80 \mathrm{mV}$ and $+40 \mathrm{mV}$ in $10-\mathrm{mV}$ increments. The cells transfected with the (a) KCNQ2 wild type (WT) $(2 \mu \mathrm{g})(n=22)$, (b) homomeric p.Thr287Ile $(n=10)(2 \mu \mathrm{g})$ and (c) heteromeric p.Thr287lle + KCNQ2 WT $(1 \mu \mathrm{g}: 1 \mu \mathrm{g})(n=10)$. (d) The conductance curves exhibited lower currents in homomeric p.Thr287Ile $[p<0.05$ ( $p$ values see Supplementary Table S1); -20 to $+40 \mathrm{mV}$ ] and heteromeric p.Thr287Ile + KCNQ2 WT compared with KCNQ2 WT $[p<0.05$ ( $p$ values 
see Supplementary Table S1); 0 to $+40 \mathrm{mV}$ )]. * homomeric p.Thr287Ile versus KCNQ2 WT; \# p.Thr287Ile + KCNQ2 WT versus KCNQ2 WT. (e) The normalized currents in homomeric p.Thr287Ile were lower $(\mathrm{G} / \mathrm{G} \max )(p<0.05 ;-30$ to $-20 \mathrm{mV}$ and $0 \mathrm{mV})$ than those in cells with KCNQ2 WT. (B) (a) The KCNQ2 WT + KCNQ3 WT $(1 \mu \mathrm{g}: 1 \mu \mathrm{g})(n=10)$ and $(\mathbf{b})$ KCNQ2 WT + p.Thr287Ile + KCNQ3 WT $(0.5 \mu \mathrm{g}: 0.5 \mu \mathrm{g}: 1 \mu \mathrm{g})(n=10)$ were analyzed. (c) The conductance curves exhibited lower currents $(p<0.05$ ( $p$ values in Supplementary Table S1); 0 to $+40 \mathrm{mV}$ ) compared with KCNQ2 WT + KCNQ3 WT. (d) The normalized currents in p.Thr287Ile + KCNQ2 WT + KCNQ3 WT were lower (G/G max) than those in cells with KCNQ2 WT + KCNQ3 WT. (C) (a) At $+40 \mathrm{mV}$ conditional stimulation, the currents in KCNQ2 WT and KCNQ2 WT + KCNQ3 WT are superior to homomeric p.Thr287Ile $(t(30)=5.66, p<0.001)$, heteromeric p.Thr287Ile + KCNQ2 WT $(t(30)=4.23, p<0.001)$, and KCNQ2 $\mathrm{WT}+$ p.Thr287Ile + KCNQ3 WT $(t(18)=4.24, p<0.001)$, correspondingly. (b) The normalized currents $(\mathrm{G} / \mathrm{Gmax})$ are different among channels, and significantly $[t(30)=2.39, p=0.027 ;-30 \mathrm{mV}]$ better in KCNQ2 WT versus homomeric p.Thr287Ile. * and \# indicate $p<0.05 ;{ }^{* *}$ and \#\# indicate $p<0.005$.

Table 2. Electrophysiological study in three KCNQ2 mutations in SF domain.

\begin{tabular}{|c|c|c|c|c|c|}
\hline $\begin{array}{c}\text { HEK293 } \\
\text { Transfection }\end{array}$ & KCNQ2 WT & $\begin{array}{c}\text { KCNQ2 WT } \\
+K C N Q 3 \mathrm{WT}\end{array}$ & p.Gly281Glu & p.Thr287Ile & p.Pro285Thr \\
\hline \multicolumn{6}{|l|}{$\begin{array}{l}\text { Homomeric variants } \\
\qquad(2 \mu \mathrm{g})\end{array}$} \\
\hline $\begin{array}{c}\mathrm{V}_{1 / 2}(\mathrm{mV}) \\
(\text { mean } \pm \mathrm{SD})(\mathrm{N})(p)\end{array}$ & $-16.9 \pm 2.0(22)$ & & $\begin{array}{c}-10.9 \pm 1.8 * *(8) \\
(p<0.001)\end{array}$ & $\begin{array}{c}-12.2 \pm 1.9^{* *}(10) \\
(p<0.001)\end{array}$ & $\begin{array}{c}-13.8 \pm 3.2 *(10) \\
(p=0.012)\end{array}$ \\
\hline $\begin{array}{c}\mathrm{K}(\mathrm{mV} / \mathrm{e} \text {-fold }) \\
(\mathrm{mean} \pm \mathrm{SD})(\mathrm{N})(p)\end{array}$ & $9.5 \pm 2.2(22)$ & & $\begin{array}{c}8.0 \pm 1.2 *(8) \\
(p=0.031)\end{array}$ & $\begin{array}{c}8.3 \pm 1.3 *(10) \\
(p=0.015)\end{array}$ & $\begin{array}{c}7.9 \pm 0.9 * *(10) \\
(p=0.009)\end{array}$ \\
\hline $\begin{array}{c}\text { Currents (pA) } \\
(\text { mean } \pm \text { SD) }(\mathrm{N})(p)\end{array}$ & $579.8 \pm 46.0(22)$ & & $\begin{array}{c}447.7 \pm 63.7 * *(8) \\
(p<0.001)\end{array}$ & $\begin{array}{c}481.8 \pm 56.9 *(10) \\
(p=0.015)\end{array}$ & $\begin{array}{c}436.0 \pm 55.0 * *(10) \\
(p<.001)\end{array}$ \\
\hline \multicolumn{6}{|l|}{$\begin{array}{c}\text { Heteromeric variants } \\
\text { (KCNQ2 + mutants) } \\
(1 \mu \mathrm{g}: 1 \mu \mathrm{g})\end{array}$} \\
\hline $\begin{array}{c}\mathrm{V}_{1 / 2}{ }^{(\mathrm{mV})} \\
(\text { mean } \pm \mathrm{SD})(\mathrm{N})(p)\end{array}$ & & & $\begin{array}{c}-13.0 \pm 2.1 *(8) \\
(p=0.010)\end{array}$ & $\begin{array}{c}-13.9 \pm 1.5 *(10) \\
(p=0.011)\end{array}$ & $\begin{array}{c}-14.8 \pm 2.1(10) \\
(p=0.073)\end{array}$ \\
\hline $\mathrm{K}(\mathrm{mV} / \mathrm{e}-$ fold $)$ & & & $8.5 \pm 1.6(8)$ & $8.7 \pm 1.1(10)$ & $8.8 \pm 1.5(10)$ \\
\hline$($ mean $\pm \mathrm{SD})(\mathrm{N})(p)$ & & & $(p=0.159)$ & $(p=0.133)$ & $(p=0.351)$ \\
\hline $\begin{array}{c}\text { Currents }(\mathrm{pA}) \\
(\mathrm{mean} \pm \mathrm{SD})(\mathrm{N})(p)\end{array}$ & & & $\begin{array}{c}490.0 \pm 38.0 *(8) \\
\quad(p=0.016)\end{array}$ & $\begin{array}{l}519.4 \pm 52.0(10) \\
\quad(p=0.056)\end{array}$ & $\begin{aligned} 518.0 & \pm 24.5(10) \\
(p & =0.74)\end{aligned}$ \\
\hline \multicolumn{6}{|l|}{$\begin{array}{l}\text { Heteromeric variants } \\
\text { (KCNQ2 + mutants } \\
+K C N Q 3) \\
(0.5 \mu \mathrm{g}: 0.5 \mu \mathrm{g}: 1 \mu \mathrm{g})\end{array}$} \\
\hline $\begin{array}{c}\mathrm{V}_{1 / 2}{ }^{(\mathrm{mV})} \\
(\text { mean } \pm \mathrm{SD})(\mathrm{N})(p)\end{array}$ & & $-20.8 \pm 1.6(10)$ & $\begin{array}{c}-18.5 \pm 2.0(8) \\
(p=0.054)\end{array}$ & $\begin{array}{c}-19.3 \pm 1.4(10) \\
(p=0.122)\end{array}$ & $\begin{array}{c}-18.8 \pm 2.2(10) \\
(p=0.061)\end{array}$ \\
\hline $\begin{array}{c}\mathrm{K}(\mathrm{mV} / \mathrm{e} \text {-fold }) \\
(\mathrm{mean} \pm \mathrm{SD})(\mathrm{N})(p)\end{array}$ & & $14.9 \pm 3.0(10)$ & $\begin{array}{c}11.1 \pm 0.7^{* *}(8) \\
(p=0.002)\end{array}$ & $\begin{array}{c}12.5 \pm 2.7(10) \\
(p=0.081)\end{array}$ & $\begin{array}{c}13.1 \pm 1.7(10) \\
(p=0.107)\end{array}$ \\
\hline $\begin{array}{c}\text { Currents (pA) } \\
(\text { mean } \pm \text { SD) }(\mathrm{N})(p)\end{array}$ & & $813.9 \pm 118.3(10)$ & $\begin{array}{c}705.0 \pm 64.4(8) \\
(p=0.051)\end{array}$ & $\begin{array}{c}753.3 \pm 94.2(10) \\
(p=0.053)\end{array}$ & $\begin{array}{c}715.2 \pm 58.3(10) \\
(p=0.054)\end{array}$ \\
\hline
\end{tabular}

$\mathrm{WT}$, wild type; $\mathrm{V}$ is the test potential; $\mathrm{V} \frac{1}{2}$, half-maximal activation voltage; $\mathrm{SD}$, standard deviation. The data were then fitted to a Boltzmann distribution of the following form: $G / G m a x=1 /\left(1+\exp \left[\left(V-V \frac{1}{2}\right) / d x\right]\right)$. Current was expressed as average currents (pA) from -80 to $+40 \mathrm{mV}$ in the transfected cells. ${ }^{*}$ indicates $p<0.05$ compared with $K C N Q 2 \mathrm{WT} ;{ }^{* *}, p<0.005$ compared with $K C N Q 2 \mathrm{WT}$. Bold font indicates significantly different from WT. Data rounded off to the first decimal place. Homomeric transfected variants and heteromeric transfected KCNQ2 $\mathrm{WT}+$ variants were compared with the current in KCNQ2 WT $(2 \mu \mathrm{g})$, respectively. Heteromeric KCNQ2 WT + KCNQ3 WT + variants were compared with the current in KCNQ2 WT + KCNQ3 WT (1 $\mu \mathrm{g}: 1 \mu \mathrm{g})$, respectively.

In heteromerically transfected KCNQ2 WT and p.Thr287Ilev $(1 \mu \mathrm{g}: 1 \mu \mathrm{g} ; n=10)$, amplitudes were significantly lower in p.Thr287Ile (Supplementary Table S1) at a conditional voltage of $10 \mathrm{mV}$ to $+40 \mathrm{mV}$ (Figure $2 \mathrm{~A}(\mathrm{~d})$ ); the normalized current was lower in p.Thr287Ile + KCNQ2 WT than did the KCNQ2 WT in HEK293 cells (Figure 2A(e)). The p.Thr287Ile + KCNQ2 WT cells expressed lower $(t(30)=1.99, p=0.056)$ currents $(519.4 \pm 52.0 \mathrm{mV}$, $n=10)$ than did the KCNQ2 WT $(579.8 \pm 46.0 \mathrm{mV} ; n=22)$ (Table 2). After transfection with 
KCNQ2 WT + KCNQ $3 \mathrm{WT}(1 \mu \mathrm{g}: 1 \mu \mathrm{g} ; n=10)$ (Figure 2B(a)) and heteromeric KCNQ2 WT + p.Thr287Ile + WT KCNQ3 (0.5 $\mu \mathrm{g}: 0.5 \mu \mathrm{g}: 1 \mu \mathrm{g} ; n=10)$ (Figure 2B(b)), the DNA ratio of which mimicked the genetic balance, amplitudes were still lower in p.Thr287lle at $0 \mathrm{mV}$ to $+40 \mathrm{mV}$ than in the KCNQ2 WT $+K C N Q 3 \mathrm{WT}$ (Figure 2B(c)) (Supplementary Table S1); the normalized current was lower in p.Thr287lle (Figure $2 \mathrm{~B}(\mathrm{~d})$ ). At a $+40 \mathrm{mV}$ conditional stimulation, the currents in KCNQ2 WT and KCNQ2 WT + KCNQ3 WT are superior to homomeric p.Thr287lle, heteromeric p.Thr287Ile + KCNQ2 WT, and KCNQ2 WT + p.Thr287Ile + KCNQ3 WT, correspondingly (Figure 2C(a)) (Supplementary Table S1). The normalized currents (G/Gmax) are different among channels, and significantly $(t(30)=2.39, p=0.027)$ better in KCNQ2 WT versus homomeric p.Thr287lle at a $-30 \mathrm{mV}$ voltage (Figure $2 \mathrm{C}(\mathrm{b})$ ). In the conduction curve in p.Thr287lle $+K C N Q 2 \mathrm{WT}$, the $\mathrm{V}_{1 / 2}$ was right shifting $3 \mathrm{mV}$ with a lower slope $\mathrm{K}$ value $[8.7 \pm 1.1$ (mV/e-fold) in p.Thr287Ile $+K C N Q 2 \mathrm{WT}$ versus $9.5 \pm 2.2$ (mV/e-fold) in KCNQ2 WT] (Table 2). In the KCNQ2 WT + p.Thr287Ile + KCNQ3 $\mathrm{WT}$, the conduction curve was closer to the curve of KCNQ2 WT +KCNQ $3 \mathrm{WT}$, but still had a worse conductance-current curve compared with KCNQ2 WT + KCNQ 3 WT.

\subsection{Electrophysiological Properties of p.Gly281Glu in KCNQ2 Mutations}

The homomeric p.Gly281Glu HEK293 cells expressed significantly lower currents (pA) than did the KCNQ2 WT cells from -10 to $+40 \mathrm{mV}$ (Figure 3A(d)) (Supplementary Table S1). The normalized currents were significantly lower in homomeric $p$.Gly281Glu cells from -30 to $-10 \mathrm{mV}$ stimulation than in KCNQ2 WT cells (Figure $3 \mathrm{~A}(\mathrm{e})$ ). In homomeric-transfected variants $(n=8), \mathrm{V}_{1 / 2}$ was $-10.9 \pm 1.8 \mathrm{mV}$; this value was right shifted $6 \mathrm{mV}$ from the $\mathrm{V}_{1 / 2}(-16.9 \pm 2.0 \mathrm{mV})$ in KCNQ2 WT. The slope $(\mathrm{K})$ was lower $[8.0 \pm 1.2(\mathrm{mV} / \mathrm{e}-\mathrm{fold})$; $t(28)=2.27, p=0.031$ ] than that of the KCNQ2 WT (Table 2). The p.Gly281Glu ratio of currents to KCNQ2 WT was $77.2 \%$. In heteromeric-transfected KCNQ2 WT cells and variants $(1 \mu \mathrm{g}: 1 \mu \mathrm{g})(n=8)$, the conductance-current curves for KCNQ2 WT + p.Gly281Glu revealed smaller increases in the current than in homomeric p.Gly281Glu (Figure 3A(d); Table 2). After transfection with the heteromeric KCNQ2 WT + p.Gly281Glu + KCNQ3 WT (0.5 $\mu \mathrm{g}: 0.5 \mu \mathrm{g}: 1 \mu \mathrm{g})(n=8)$, the current amplitudes remained lower in the KCNQ2 WT + p.Gly281Glu + KCNQ3 WT cells than in the KCNQ2 WT + KCNQ3 WT cells (Figure 3B(c,d)). At a $+40 \mathrm{mV}$ conditional stimulation, the currents in KCNQ2 WT were superior to homomeric p.Gly281Glu (1534.5 \pm 141.9 versus $1109.4 \pm 112.6, \mathrm{pA} / \mathrm{pF})(\mathrm{t}(30)=8.76, p<0.001)$ and to heteromeric p. Gly281Glu + KCNQ2 WT $(1534.5 \pm 141.9$ versus $1323.1 \pm 81.0$, $\mathrm{pA} / \mathrm{pF})(\mathrm{t}(30)=4.18, p<0.001) ; K C N Q 2 \mathrm{WT}+K C N Q 3 \mathrm{WT}$ were superior to KCNQ2 WT + p. Gly281Glu + KCNQ3 WT (2474.3 \pm 395.3 versus $2120.0 \pm 65.9, \mathrm{pA} / \mathrm{pF})(\mathrm{t}(18)=2.49$, $p=0.024$ ), correspondingly (Figure 3C(a)) (Supplementary Table S1). The value of G/Gmax was significantly low at a conditional voltage of $-30 \mathrm{mV}$ in homomeric p.Gly281Glu $[\mathrm{t}(28)=2.48, p=0.024]$ and in heteromeric KCNQ2 WT + p. Gly281Glu + KCNQ3 WT $[\mathrm{t}(16)=2.81, p=0.012]$ compared with WT, correspondingly (Figure $3 \mathrm{C}(\mathrm{b}))$. The cell currents in homomeric p.Gly281Glu, hetromeric p. Gly281Glu + KCNQ2 WT, and KCNQ2 WT + p. Gly281Glu + KCNQ3 WT were impaired to be lower than in the WT.

\subsection{Conductance-Current Curves in p.Thr287Ile, p.Gly281Glu, p.Pro285Thr and KCNQ2 WT}

The p.Pro285Thr conduction curve is exhibited in Figure 4. Among the 3 mutations, the $\mathrm{V}_{1 / 2}$ in homomeric channels was $-13.8 \pm 3.2 \mathrm{mV}$ in p.Pro285Thr, $-12.2 \pm 1.9 \mathrm{mV}$ in p.Thr287Ile, $-10.9 \pm 1.8 \mathrm{mV}$ in p.Gly281Glu, and $-16.9 \pm 2.0 \mathrm{mV}$ in the KCNQ2 WT. There was a right shift in the curve of $\mathrm{V}_{1 / 2}$ at $3.1 \mathrm{mV}$ in p.Pro285Thr, at $4.7 \mathrm{mV}$ in p.Thr287Ile [ $t(30)=-4.51, p<0.001]$, and at $6 \mathrm{mV}$ in p.Gly281Glu [ $t(28)=-5.84, p<0.001]$, compared to that of the $\mathrm{V}_{1 / 2}$ in KCNQ2 WT. The slope (K) was lower in p.Thr287lle $[8.3 \pm 1.3,(\mathrm{mV} / \mathrm{e}$-fold); $t(30)=2.59, p=0.015]$ and p.Gly281Glu $[8.0 \pm 1.2,(\mathrm{mV} / \mathrm{e}-$ fold $)$; $t(28)=2.27$, conditiona 0.031$]$ compared with that in KCNQ2 WT [9.5 $\pm 2.2,(\mathrm{mV} / \mathrm{e}-$ fold $)]$ (Table 2). The variant-to-WT currents ratio was $83.1 \%$ in homomeric p.Thr287lle and $77.2 \%$ in homomeric p.Gly281Glu. In heteromeric-transfected KCNQ2 WT cells and variants, the conductance-current curves were lowest in KCNQ2 WT + p.Gly281 (Table 2). All three 
mutations in homomeric currents were lower in $\mathrm{V}_{1 / 2}$, the $\mathrm{K}$ slope and currents (Table 2). After the transfection with the heteromeric KCNQ2 WT and variants and with the KCNQ3 WT $(0.5 \mu \mathrm{g}: 0.5 \mu \mathrm{g}: 1 \mu \mathrm{g})$, the current amplitudes remained lower in the mutations (Table 2 and Supplementary Table S1).

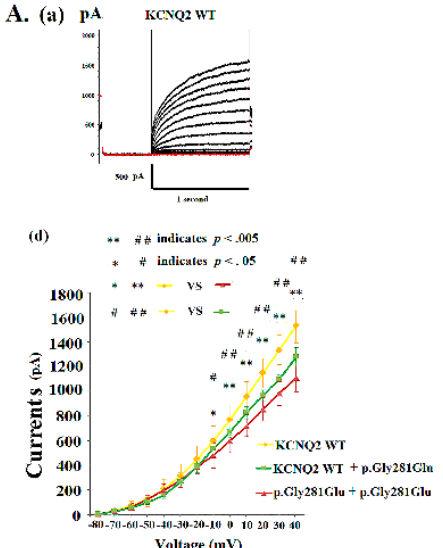

B. (a)

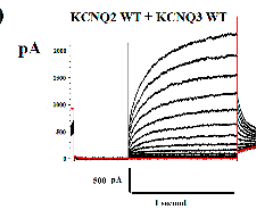

(c)

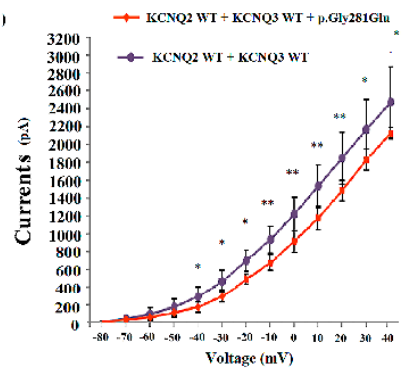

C. (a)

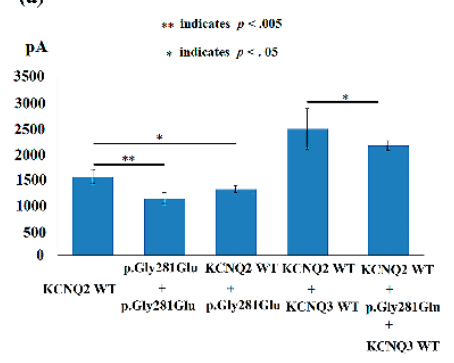

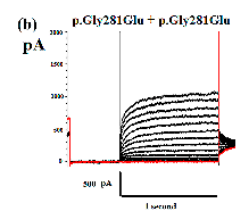

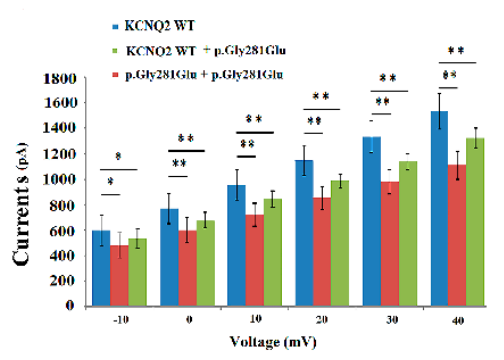

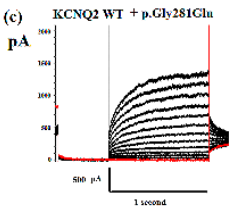

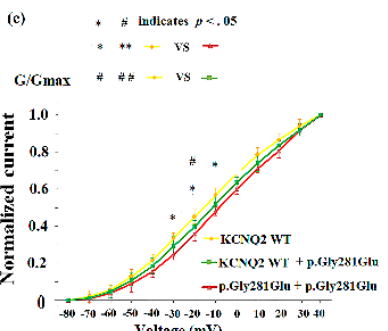

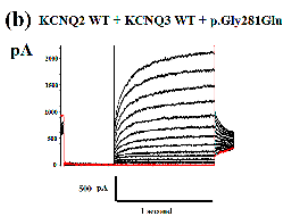
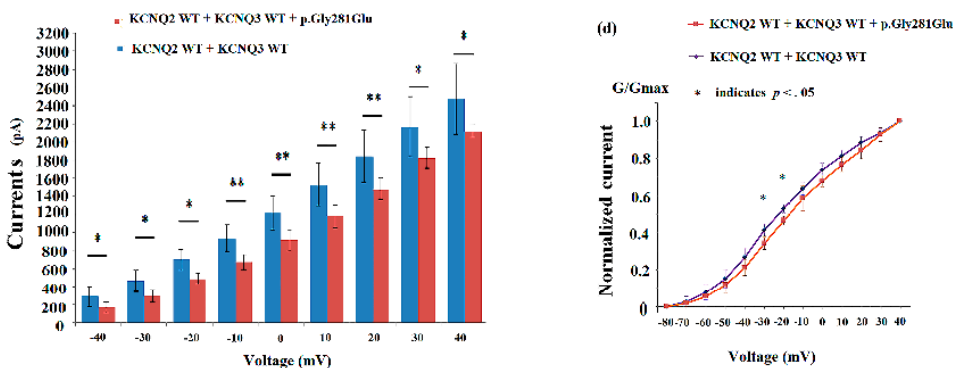

(b)

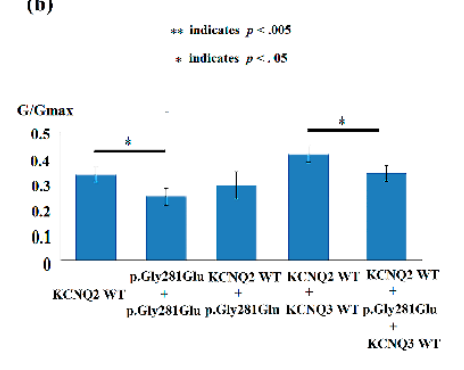

$-30 \mathrm{mV}$ conditienal stimulatio

Figure 3. (A) The cells transfected with the (a) KCNQ2 wild type (WT) $(2 \mu \mathrm{g})(n=22)$, (b) homomeric p.Gly281Glu $(2 \mu \mathrm{g})(n=8)$ and (c) heteromeric p.Gly281Glu + KCNQ2 WT $(1 \mu \mathrm{g}: 1 \mu \mathrm{g})(n=8)$ were analyzed. The voltage-clamp steps were from $-80 \mathrm{mV}$ and $+40 \mathrm{mV}$ in $10-\mathrm{mV}$ increments. (d) Cells transfected with p.Gly281Glu exhibited lower [ $p<0.05$ ( $p$ values see Supplementary Table S1); $-10+40 \mathrm{mV}$ ) currents in homomeric p.Gly281Glu and in heteromeric p.Gly281Glu + KCNQ2 WT [ $p<0.05$ ( $p$ values see Supplementary Table S1); $-10+40 \mathrm{mV}$ ] compared with KCNQ2 WT, correspondingly. * homomeric p. Gly281Glu versus KCNQ2 WT; \# p. Gly281Glu + KCNQ2 WT versus KCNQ2 WT. (e) The normalized currents in homomeric p. Gly281Glu were lower (G/G max) $(p<0.05$; -30 to $-10 \mathrm{mV})$ than those in cells with KCNQ2 WT. (B) The (a) KCNQ2 WT + KCNQ3 WT (1 $\mu \mathrm{g}: 1 \mu \mathrm{g})$ 
$(n=10)$ and (b) KCNQ2 WT + p. Gly281Glu + KCNQ3 WT $(0.5 \mu \mathrm{g}: 0.5 \mu \mathrm{g}: 1 \mu \mathrm{g})(n=8)$ were analyzed. (c) The KCNQ2 WT + p.Gly281Glu + KCNQ3 WT exhibited lower currents $[p<0.05$ ( $p$ values see Supplementary Table S1)] compared with KCNQ2 WT + KCNQ3 WT from -40 to $+40 \mathrm{mV}$ conditional stimulation. (d) The normalized currents in p.Gly281Glu + KCNQ2 WT + KCNQ3 WT were lower (G/G max) than those in cells with KCNQ2 WT + KCNQ3 WT at $-30[\mathrm{t}(16)=2.81, p=0.012]$ and $-20 \mathrm{mV}[\mathrm{t}(16)=2.72, p=0.018]$ stimulation. (C) (a) At $+40 \mathrm{mV}$ stimulation, the currents in KCNQ2 $\mathrm{WT}$ and KCNQ2 WT + KCNQ3 WT are superior to homomeric p. Gly281Glu (t(30)=8.76, $p<0.001)$, heteromeric p. Gly281Glu + KCNQ2 WT $((\mathrm{t}(30)=4.18, p<0.001)$, and KCNQ2 WT + p. Gly281Glu + KCNQ3 WT $(\mathrm{t}(18)=2.49, p=0.024)$, correspondingly. (b) The value of G/Gmax was significantly low at a conditional voltage of $-30 \mathrm{mV}$ in homomeric p. Gly281Glu $[t(28)=2.48, p=0.024]$ and heteromeric KCNQ2 WT + p. Gly281Glu + KCNQ3 WT $(t(16)=2.81, p=.012)$ compared with WT, correspondingly. ${ }^{*}$ and \# indicate $p<0.05 ;{ }^{* *}$ and \#\# indicate $p<0.005$.

A.
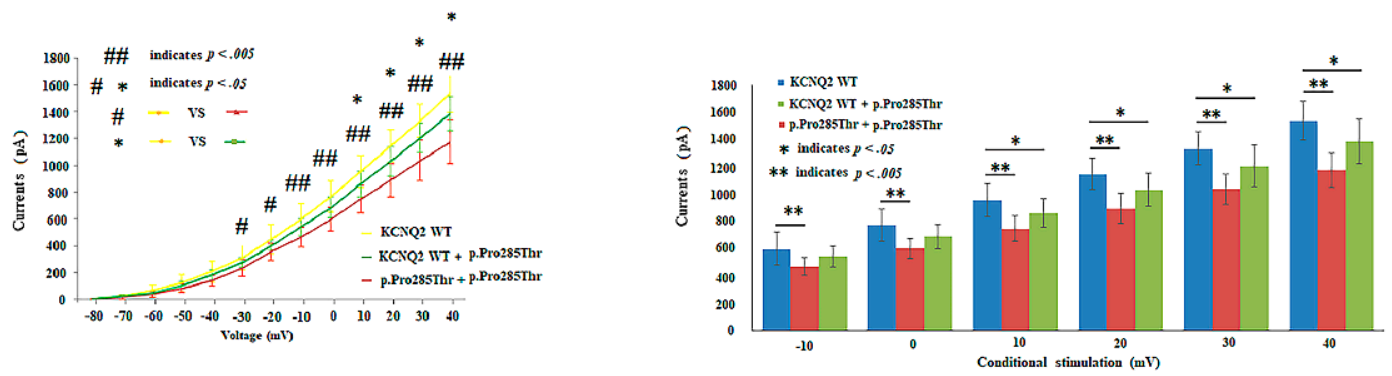

B.
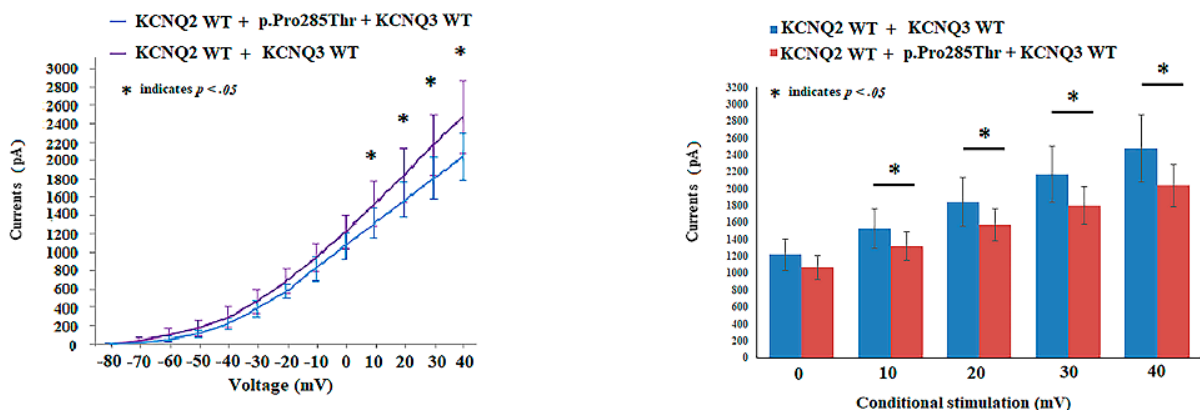

Figure 4. (A) Cells transfected with p.Pro285Thr exhibited lower $[p<0.05$ ( $p$ values see Supplementary Table S1); -10 to $+40 \mathrm{mV}$ ] currents in homomeric p.Pro285Thr and in heteromeric p.Pro285Thr + KCNQ2 WT $[p<0.05$ ( $p$ values see Supplementary Table S1); +10 to $+40 \mathrm{mV}$ ] compared with KCNQ2 WT, correspondingly. * and \# indicate $p<0.05 ;{ }^{* *}$ and \#\# indicate $p<0.005$. (B) The KCNQ2 WT + p.Pro285Thr $+K C N Q 3 \mathrm{WT}$ exhibited lower current densities $[p<0.05$ ( $p$ values see Supplementary Table S1)] compared with KCNQ2 WT + KCNQ3 WT from +10 to $+40 \mathrm{mV}$ conditional stimulation. * indicates $p<0.05$.

In the heteromeric channels added with KCNQ3 and KCNQ2 WT, the p.Gly281Glu has lower normalized currents than the p.Thr287lle and p.Pro285Thr at a $-30 \mathrm{mV}$ stimulation (Figure 5 and Supplementary Table S1).

Tail currents in the WT and mutations are shown (Figure 6A-C). The currents (pA) at a $+40 \mathrm{mV}$ potential showed that currents were lower in homomeric p.Gly281Glu (513.2 \pm 64.7 ; $p=0.022)$ and in p.Thr287Ile $(499.7 \pm 34.6 ; p=0.007)$ than the currents in KCNQ2 WT $(625.6 \pm 58.1)$ (Figure 6D). However, the tail currents of the p.Gly281Glu and p.Thr287lle cells were increased in the KCNQ2 WT + p.Gly281Glu (656.5 \pm 49.4$)$ and in the KCNQ2 $\mathrm{WT}+$ p.Thr287lle (646.6. \pm 87.65$)$ at a $+40 \mathrm{mV}$ conditional voltage. In the heteromeric Kv7.2 + Kv7.3 and Kv7.2 + Kv7.3 + mutants, the currents were increased in p.Gly281Glu $(1078.5 \pm 153.8 ; p=0.010)$ and in p.Thr287lle (1111.6 $\pm 169.6 ; p=0.033)$, and were still lower than in those in the KCNQ2 WT + KCNQ3 WT cells (1286.7. \pm 112.0 ) (Figure 6D). 


\subsection{Phenotypes, KCNQ2 Protein Expression, and Configuration Change on Cell Membranes}

After analyzing KCNQ2 protein expression for various variants, KCNQ2 protein expression on cell membranes did not differ significantly $(n=3)$ in KCNQ2 WT, p.T287I and p.Gly281Glu (Figure 7A,B).

All p.Thr287Ile, p.Pro285Thr and p.Gly281Glu mutations are located in the SF domain of the KCNQ2 channel. The computational model for p.Thr287Ile, p.Pro285Thr and p.Gly281Glu mutations predicted to change the configuration of the pore. For all three mutations, it was predicted that the diameter of the pores are different compared to those of the KCNQ2 WT (Figure 8A,B).

\subsection{Neurodevelopmental Outcomes Related to Mutations in the SF of KCNQ2}

For the 35 mutations in the SF domain, using changes in amino acid weight between the WT and the KCNQ2 mutations to predict EE resulted in $80.0 \%$ sensitivity, $80 \%$ specificity, a positive prediction rate of $96.0 \%$, and a negative prediction rate of $40.0 \%(p=0.006$, $\chi^{2}(1, n=35)=7.56$; odds ratio $16.0,95 \%$ confidence interval, 1.50 to 170.63) (Table 3 ).

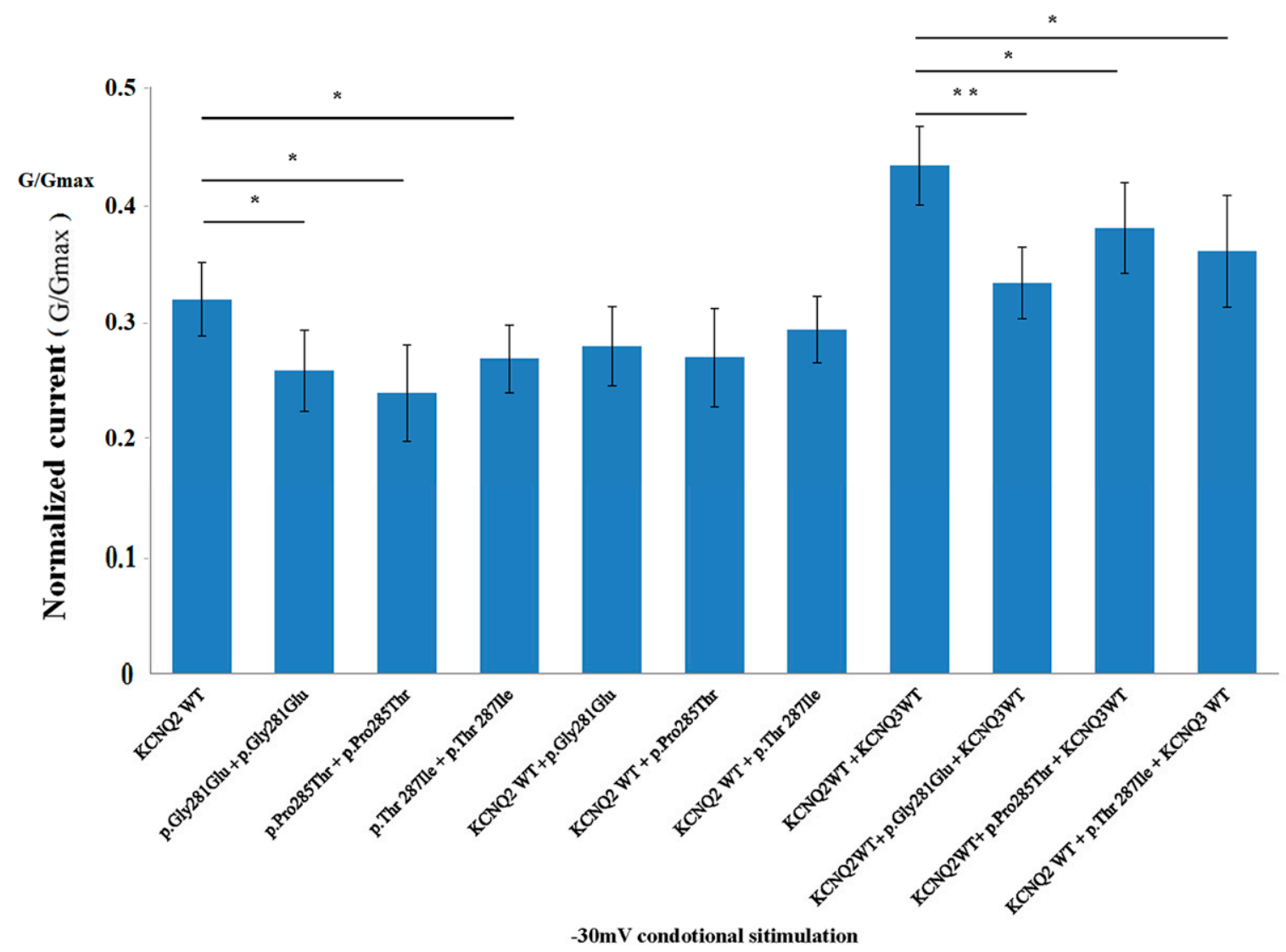

Figure 5. The normalized current in p.Thr287Ile, p.Gly281Glu, p.Pro285Thr and wild type demonstrated the homomerically transfections in 3 mutations that were significant lower than the wild type at $-30 \mathrm{mV}$ stimulations. In heteromerically transfected with $K C N Q 3+K C N Q 2+$ variants, the p.Gly281Glu exhibited lower normalized currents than p.Thr287Ile, p.Pro285Thr and KCNQ3 $+K C N Q 2$ wild type. ${ }^{*}$ indicates $p<0.05 ;{ }^{* *}, p<0.005$. KCNQ2 WT and mutant KCNQ2 alleles were transfected into HEK293 cells in homomeric mutants $(2 \mu \mathrm{g})$, heteromeric KCNQ2 + mutants $(1 \mu \mathrm{g}+1 \mu \mathrm{g})$, and heteromeric KCNQ2 WT + variants + KCNQ3 WT $(0.5 \mu \mathrm{g}: 0.5 \mu \mathrm{g}: 1 \mu \mathrm{g})$, respectively. 
A.
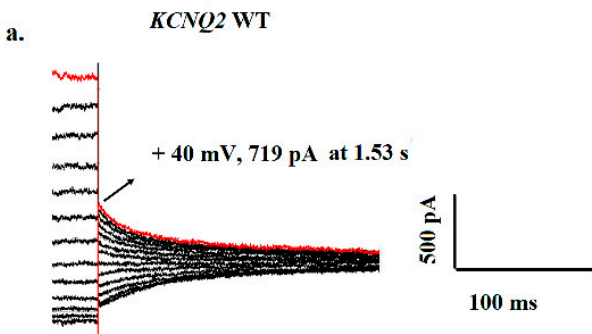

B. a. p.Gly281Glu + p.Gly281Glu

KCNQ2 WT + p.Gly281Glu

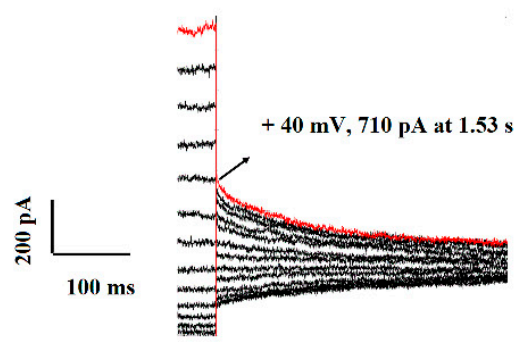

C. $\mathbf{a}$.

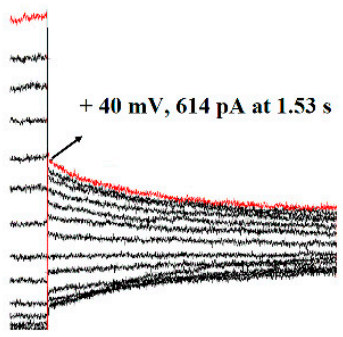

b.

$K C N Q 2$ WT + p.Thr287Ile
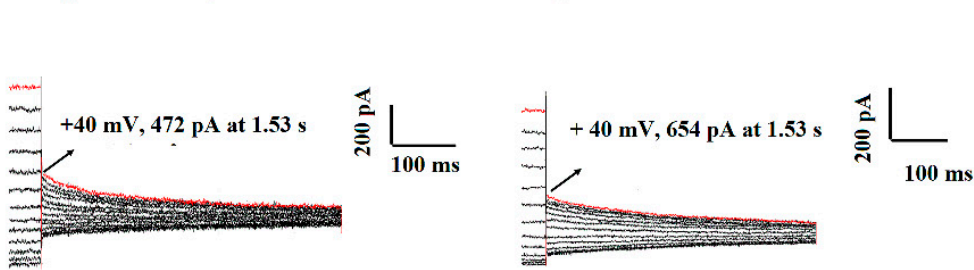

c. $\quad K C N Q 2 \mathrm{WT}+$ p.Gly281Glu $+K C N Q 3 \mathrm{WT}$

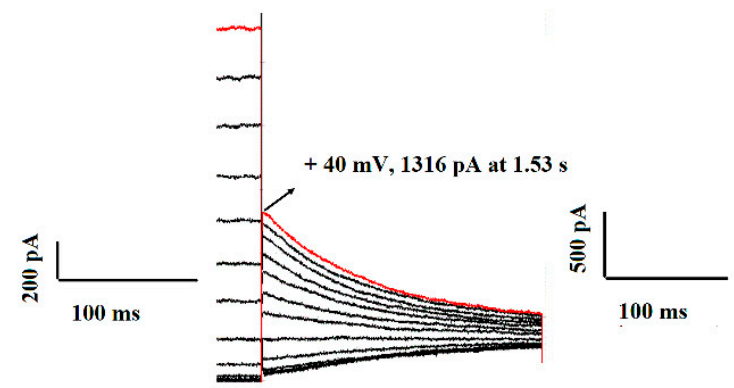

c. $\quad K C N Q 2 \mathrm{WT}+$ p.Thr287Ile $+K C N Q 3 \mathrm{WT}$

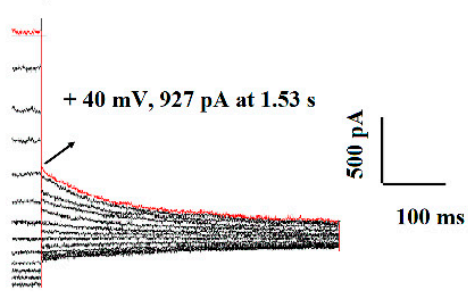

D.

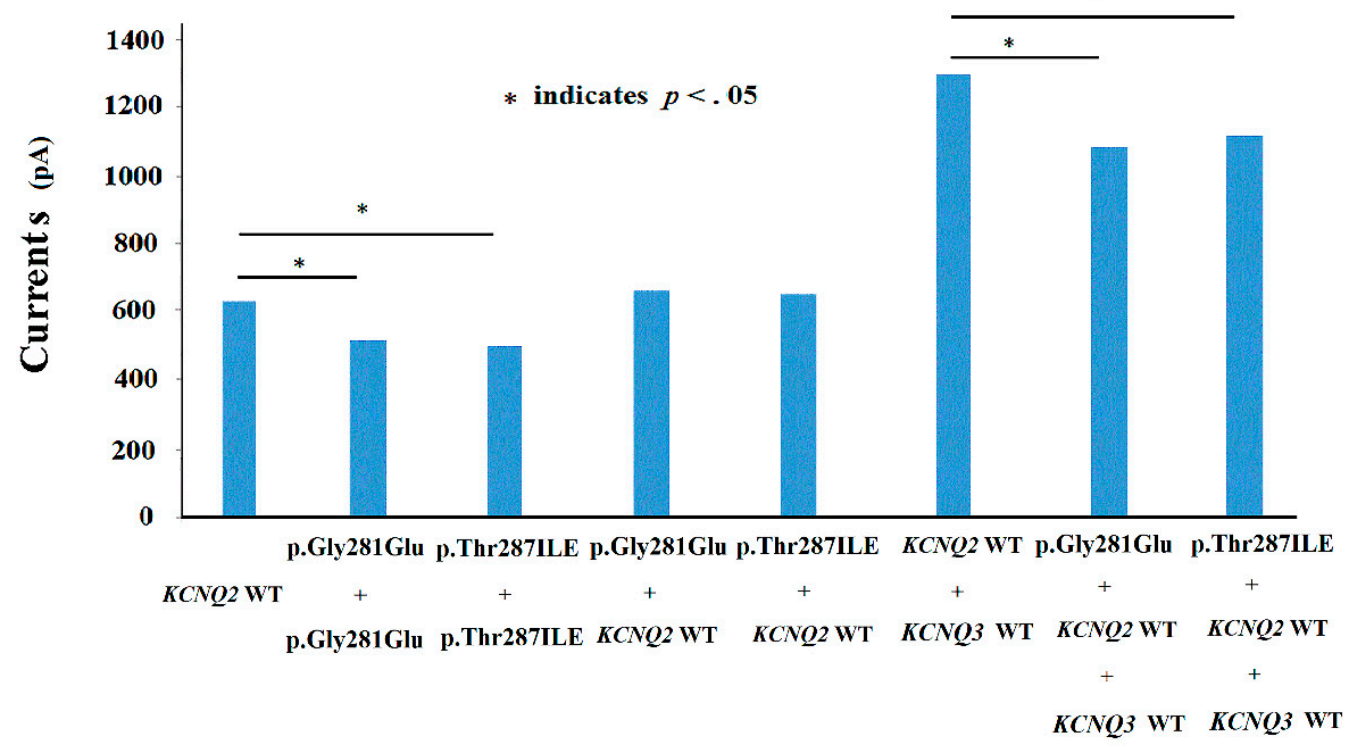

Figure 6. (A) Tail currents in the $\mathrm{WT}$ and mutations are shown at $+40 \mathrm{mV}$ conditional voltage. (a) KCNQ2 WT $(2 \mu \mathrm{g})(n=22),(\mathbf{b}) \mathrm{KCNQ} 2 \mathrm{WT}+\mathrm{KCNQ} 3 \mathrm{WT}(1 \mu \mathrm{g}: 1 \mu \mathrm{g})(n=10)$. (B) (a) The homomeric p.Gly281Glu $(n=8)$, (b) heteromeric p.Gly281Glu + KCNQ2 WT $(1 \mu \mathrm{g}: 1 \mu \mathrm{g})(n=8)$, (c) heteromeric KCNQ2 WT + p.Gly281Glu + KCNQ3 WT $(0.5 \mu \mathrm{g}: 0.5 \mu \mathrm{g}: 1 \mu \mathrm{g})(n=8)$. (C) (a) The 
homomeric p.Thr287Ile $(2 \mu \mathrm{g})(n=10)$, (b) heteromeric p.Thr287Ile + KCNQ2 WT $(1 \mu \mathrm{g}: 1 \mu \mathrm{g})(n=10)$, (c) heteromeric KCNQ2 WT + p.Thr287Ile + KCNQ3 WT $(0.5 \mu \mathrm{g}: 0.5 \mu \mathrm{g}: 1 \mu \mathrm{g})(n=10)$. (D) The homomeric variants had lower currents in p.Gly281Glu (513.2 $\pm 64.7 ; p=0.022)$ and in p.Thr287lle $(499.7 \pm 34.6 ; p=0.007)$ than the currents in the KCNQ2 WT $(625.6 \pm 58.1)$. In the heteromeric Kv7.2 + Kv7.3 and Kv7.2 + Kv7.3 + mutants, the currents were lower in p.Gly281Glu (1078.5 $\pm 153.8 ; p=$ $0.010)$ and in p.Thr287Ile $(1111.6 \pm 169.6 ; p=0.033)$, than in those in the KCNQ2 WT + KCNQ3 WT cells $(1286.7 \pm 112.0)$. ${ }^{*}$ indicates $p<0.05$.

A.

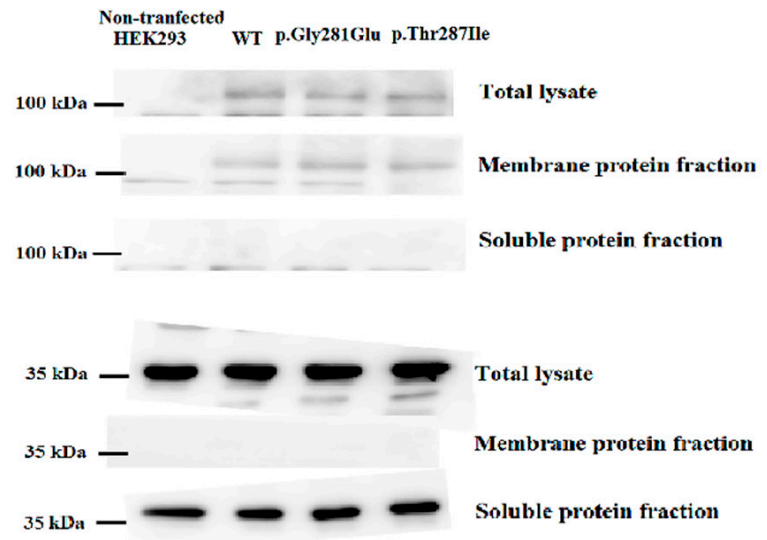

B.

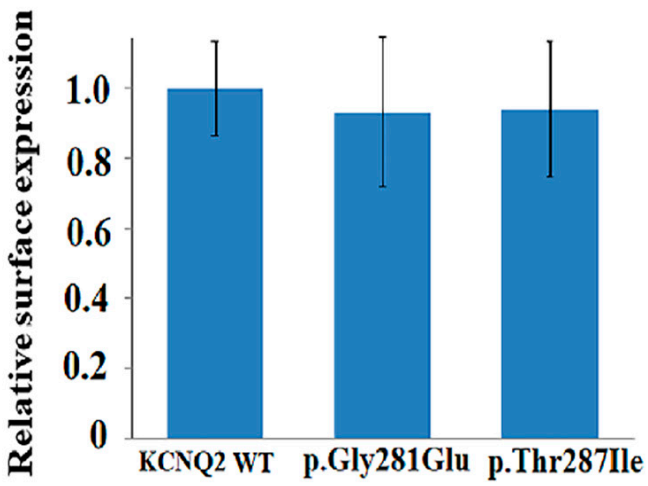

Figure 7. (A) Western blotting demonstrated the protein expression in KCNQ2 WT, p.Thr287lle, and p.Gly281Glu. KCNQ2 protein expression was not significantly $(n=3)$ (Supplementary Figure S1) different in p. T287I and p. Gly281Glu. Protein expression on cell membranes did not differ significantly for both mutations and KCNQ2 WT. (B) Western blotting demonstrated the protein expression in KCNQ2 WT, p.Thr287lle, and p.Gly281Glu. KCNQ2 protein expression was not significant $(n=3)$.
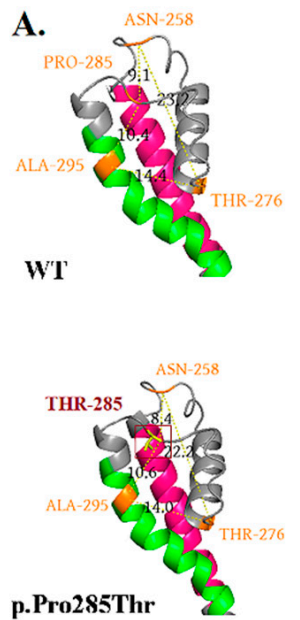

B. $\mathrm{a}$
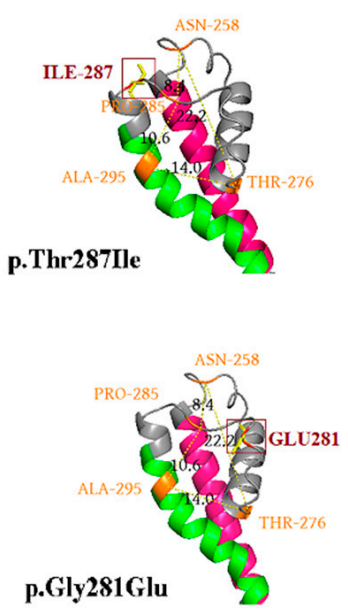
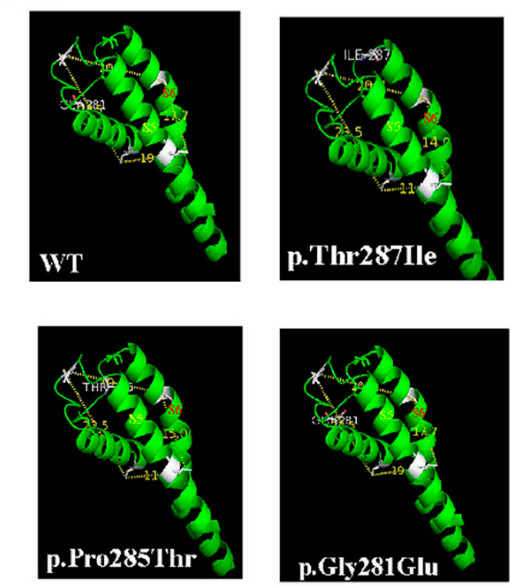

b
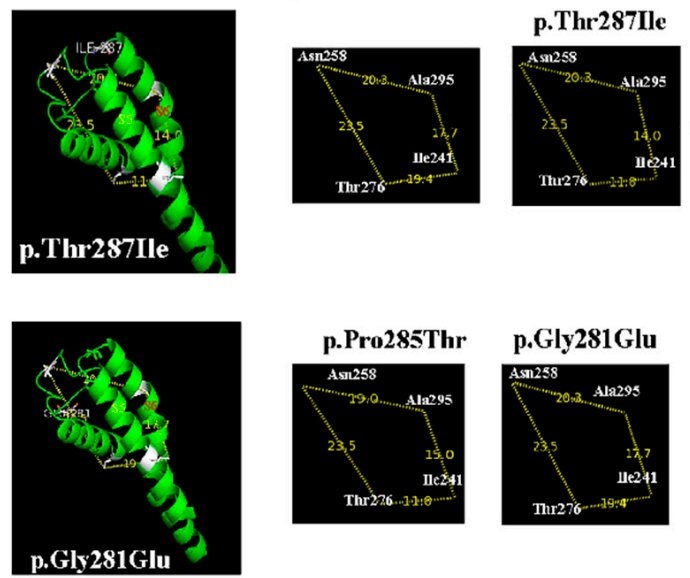

p.Pro285Thr
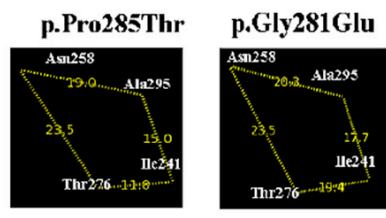

Figure 8. Schematic representation of the KCNQ2 subunit with the position of the mutations of p.Thr287lle. The predicted 3D model of the KCNQ2 channel protein (c5vmsA_.1.pdb) was then used to analyze the structural differences between KCNQ2 WT and mutations by using SwissPdbViewer and PyMOL, respectively. Mutation (p.Thr287lle, p.Gly281Glu and p.Pro285Thr) sites at the selectivity filter (SF) might alter accessibility for potassium ions through the channels. The p.Thr287Ile, p.Gly281Glu and p.Pro285Thr are located in the SF of the pore domain and cause the $K C N Q 2$ protein configuration of pore domain change according to the molecular model. (A) The pore 
change was determined by calculating the distances from Asn (p.258) to Pro (p.285), Pro (p.285) to Ala (p.295), Ala (p.295) to Thr (p. 276), and Thr (p.276) to Asn (p.258), respectively. The diameters of the KCNQ2 channel pores were determined by calculating the distance from protein 258 to 285 (A), 285 to 295 (B), 295 to 276 (C), and 276 to 258 (D). The pore configuration was expressed as A $\times \mathrm{B} \times \mathrm{C} \times \mathrm{D}$. The mutations change the configurations of pores in p.Thr287Ile (from 31,617.3 in WT changed to 27,673.6), in p.Gly281Glu (from 31,617.3 changed to 27,673.6) and p.Pro285Thr (from $31,617.3$ to $27,673.6)$. (B) (a) The pore change were also determined by calculating the distances from Asn (p.258) to Thr (p.276), Thr (p.276) to Ile (p.241), Ile (p.241) to Ala (p.295), and Ala (p.295) to Asn (p.258), respectively. (b) The pore configurations were changed by the mutations of p.Thr287Ile and p.Pro285Thr. Mutations changed configurations of pores in p.Thr287Ile, p.Gly281Glu, and p.Pro285Thr. The diameter of the KCNQ2 channel pore was determined by calculating the distance from protein 258 to 276 (A1), 276 to 295 (B1), 241 to 276 (C1), and 241 to 295 (D1). The pore distance was expressed as A1 $\times \mathrm{B} 1 \times \mathrm{C} 1 \times \mathrm{D} 1$. Mutations changed the configurations of pores in p.Thr287Ile (from 163,809.4 in the WT to 78,808.7), in p.Gly281Glu (not different from 163,809.4 in WT), and p.Pro285Thr (from $163,809.4$ in the WT to $77,691.0$ ).

Table 3. Among 35 mutations in the selectivity filter domain, changes in amino acid weight between the WT and the mutations are demonstrated.

\begin{tabular}{|c|c|c|c|c|c|c|c|c|}
\hline $\begin{array}{c}\text { KCNQ2 } \\
\text { Genotype }\end{array}$ & WT & $\begin{array}{c}\text { Weight of } \\
\text { Amino } \\
\text { Acid of } \\
\text { KCNQ2 } \\
\text { WT }\end{array}$ & $\begin{array}{l}\text { Amino Acid } \\
\text { Polarity }\end{array}$ & $\begin{array}{c}\text { Amino } \\
\text { Acid } \\
\text { Change }\end{array}$ & $\begin{array}{l}\text { Weight of } \\
\text { Mutated } \\
\text { Amino } \\
\text { Acid }\end{array}$ & $\begin{array}{c}\text { Mutated } \\
\text { Amino Acid } \\
\text { Polarity }\end{array}$ & Phenotype & References \\
\hline Ala253Thr & Ala & 89 & $\mathrm{~N}$ & Thr & 119 & $\mathrm{Y}$ & $\mathrm{EE}$ & [44] \\
\hline Gly256Trp & Gly & 75 & $\mathrm{~N}$ & $\operatorname{Trp}$ & 204 & $\mathrm{Y}$ & $\mathrm{EE}$ & [29] \\
\hline Asn258Ser & Asn & 132 & $\mathrm{Y}$ & Ser & 105 & $\mathrm{Y}$ & BFNC & [45] \\
\hline Asp259Tyr & Asp & 133 & Acid R group & Tyr & 181 & $\mathrm{Y}$ & BFNC & [46] \\
\hline Asp259Gly & Asp & 133 & Acid R group & Gly & 75 & $\mathbf{N}$ & BFNC & [47] \\
\hline Asp259Glu & Asp & 133 & Acid R group & Glu & 147 & Acid R group & EE & [29] \\
\hline Ala265Val & Ala & 89 & $\mathrm{~N}$ & Val & 117 & $\mathrm{~N}$ & $\mathrm{EE}$ & [48] \\
\hline Ala265Pro & Ala & 89 & $\mathrm{~N}$ & Pro & 115 & $\mathrm{~N}$ & $\mathrm{EE}$ & [7] \\
\hline Ala265Thr & Ala & 89 & $\mathrm{~N}$ & Thr & 119 & $\mathrm{Y}$ & $\mathrm{EE}$ & [49] \\
\hline Leu268Phe & Leu & 131 & $\mathrm{~N}$ & Phe & 165 & $\mathrm{~N}$ & $\mathrm{EE}$ & [50] \\
\hline Trp269Leu & Trp & 204 & $\mathbf{Y}$ & Leu & 131 & $\mathbf{N}$ & $\mathrm{EE}$ & [51] \\
\hline Trp270Arg & Trp & 204 & $\mathbf{Y}$ & Arg & 174 & Basic R group & $\mathrm{EE}$ & [52] \\
\hline Gly271Val & Gly & 75 & $\mathrm{~N}$ & Val & 117 & $\mathrm{~N}^{\circ}$ & BFIC & [53] \\
\hline Ile273Asn & Ile & 131 & $\mathrm{~N}$ & Asn & 132 & $\mathrm{Y}$ & EE & [51] \\
\hline Thr274Met & Thr & 119 & Y & Met & 149 & $\mathrm{~N}$ & $\mathrm{EE}$ & [7] \\
\hline Thr276Ile & Thr & 119 & $\mathrm{Y}$ & Ile & 131 & $\mathrm{~N}$ & $\mathrm{EE}$ & [54] \\
\hline Thr277Ile & Thr & 119 & $\mathrm{Y}$ & Ile & 131 & $\mathrm{~N}$ & $\mathrm{EE}$ & [55] \\
\hline Gly279Cys & Gly & 75 & $\mathrm{~N}$ & Cys & 121 & $\mathrm{Y}$ & $\mathrm{EE}$ & [44] \\
\hline Gly281 Trp & Gly & 75 & $\mathrm{~N}$ & Trp & 204 & $\mathrm{Y}$ & $\mathrm{EE}$ & [50] \\
\hline Gly281Arg & Gly & 75 & $\mathrm{~N}$ & Arg & 174 & Basic R group & $\mathrm{EE}$ & [8] \\
\hline Gly281Glu & Gly & 75 & $\mathrm{~N}$ & Glu & 147 & Acid R group & $\mathrm{EE}$ & The study \\
\hline Gly281Trp & Gly & 75 & $\mathrm{~N}$ & $\operatorname{Trp}$ & 204 & $\mathrm{Y}^{0}$ & $\mathrm{EE}$ & [50] \\
\hline Asp282Asn & Asp & 133 & Acid R group & Asn & 132 & $\mathrm{Y}$ & $\mathrm{EE}$ & [56] \\
\hline Tyr284Asp & Tyr & 181 & $\mathbf{Y}^{\mathrm{S}}$ & Asp & 133 & Acid R group & EE & [46] \\
\hline Tyr284Cys & Tyr & 181 & $\mathbf{Y}$ & Cys & 121 & $\mathrm{Y}^{\mathrm{O}}$ & BFNC & [3] \\
\hline Pro285Thr & Pro & 115 & $\mathrm{~N}$ & Thr & 119 & $\mathrm{Y}$ & $\mathrm{EE}$ & The study \\
\hline Pro285Ser & Pro & 115 & $\mathbf{N}$ & Ser & 105 & $\mathrm{Y}$ & EE & [57] \\
\hline Pro285His & Pro & 115 & $\mathrm{~N}$ & His & 155 & Basic R group & $\mathrm{EE}$ & [6] \\
\hline Thr287Ile & Thr & 119 & $\mathrm{Y}$ & Ile & 131 & N & $\mathrm{EE}$ & The study \\
\hline Thr287Pro & Thr & 119 & $\mathbf{Y}$ & Pro & 115 & $\mathbf{N}$ & $\mathrm{EE}$ & [58] \\
\hline Thr287Asn & Thr & 119 & $\mathrm{Y}$ & Asn & 132 & $\mathrm{Y}$ & $\mathrm{EE}$ & [49] \\
\hline Gly290Asp & Gly & 75 & $\mathrm{~N}$ & Asp & 133 & Acid R group & $\mathrm{EE}$ & [7] \\
\hline Gly290Ser & Gly & 75 & $\mathrm{~N}$ & Ser & 105 & $\mathrm{Y}^{\mathrm{T}}$ & $\mathrm{EE}$ & [49] \\
\hline
\end{tabular}


Table 3. Cont.

\begin{tabular}{|c|c|c|c|c|c|c|c|c|}
\hline $\begin{array}{c}\text { KCNQ2 } \\
\text { Genotype }\end{array}$ & WT & $\begin{array}{c}\text { Weight of } \\
\text { Amino } \\
\text { Acid of } \\
\text { KCNQ2 } \\
\text { WT }\end{array}$ & $\begin{array}{l}\text { Amino Acid } \\
\text { Polarity }\end{array}$ & $\begin{array}{l}\text { Amino } \\
\text { Acid } \\
\text { Change }\end{array}$ & $\begin{array}{l}\text { Weight of } \\
\text { Mutated } \\
\text { Amino } \\
\text { Acid }\end{array}$ & $\begin{array}{c}\text { Mutated } \\
\text { Amino Acid } \\
\text { Polarity }\end{array}$ & Phenotype & References \\
\hline Arg291Ser & Arg & 174 & Basic R group & Ser & 105 & $\mathbf{Y}$ & EE & [59] \\
\hline Arg291Gly & Arg & 174 & Basic R group & Gly & 75 & $\mathbf{N}$ & EE & [60] \\
\hline
\end{tabular}

WT indicates wild type; $\mathrm{N}$, non-polar amino acids; $\mathrm{Y}$, polar amino acids; BFNC, benign familial neonatal convulsions; EE, epileptic encephalopathy. Bold indicates the mutated amino acid that was lighter than that of the WT.

\# Among 35 mutations in the SF domain, using changes in amino acid weight between the WT and the KCNQ2 channel to predict EE resulted in $80.0 \%$ sensitivity, $80 \%$ specificity, a positive prediction rate of $96.0 \%$, and a negative prediction rate of $40.0 \%\left(p=0.006, \chi^{2}(1, n=35)=7.56\right.$; odds ratio $16.0,95 \%$ confidence interval, 1.50 to 170.63$)$.

\subsection{Neurodevelopmental Outcomes Related to Mutations in the SF of KCNQ2}

Among the 35 mutations in the SF (Table 3 and Figure 5), the 5 that caused BFNCs were p.Asn258Ser, p.Asp259Thr, p.Asp259Tyr, p.Gly271Val and p.Tyr284Cys. Of those, 3 (60\%; p.Asn258Ser, p.Asp259Thr, and p.Tyr284Cys) exhibited a mutated amino acid that was lighter than that of the WT (Table 3). The p.Gly271Val and p.Asp259Tyr mutations exhibited an increased molecular weight of the new amino acid. An analysis of pore diameters indicated relatively larger pores than in the others in the 5 mutations. Mutations that caused neonatal-onset EE represented the majority of mutations (85.7\%), and they exhibited larger mutated protein weights (Table 3 ) and a smaller pore diameter than those in mutations that caused BFNCs (Table 3). This finding indicates that a high mutated amino acid weight could be an obstacle to pore size, a phenomenon that may be critical for determining neurodevelopmental outcomes. For the 35 mutations in the SF domain, using changes in amino acid weight between the WT and the KCNQ2 mutations to predict EE resulted in $80.0 \%$ sensitivity, $80 \%$ specificity, a positive prediction rate of $96.0 \%$, and a negative prediction rate of $40.0 \%\left(p=0.006, \chi^{2}(1, n=35)=7.56\right.$; odds ratio $16.0,95 \%$ confidence interval, 1.50 to 170.63$)$.

\section{Discussion}

The present study confirmed that KCNQ2 and KCNQ3 channels of p.Thr287Ile, p.Pro285Thr and p.Gly281Glu have dysfunctional effects on the Kv7.2 channel. Functional current changes were more severe in homomerically transfected p.Thr287Ile, p.Pro285Thr and p.Gly281. When concurrently heteromerically transfected with KCNQ3 and KCNQ2 mutants, the current changes were less severe but still lower in p.Thr287lle, p.Pro285Thr and p.Gly281Glu than that of the WT. The pore loop between S5 and S6 contains a highly conserved SF that controls $\mathrm{K}+$ permeability and selectivity [33]. Threonine (Thr) was hydrophilic and changed to isoleucine (Ile), which is hydrophobic. The p.Thr287lle is located in the SF of the pore domain and can cause the KCNQ2 protein pore domain to change according to the molecular model. The mutation (p.Thr287Ile) by the study matched the American College of Medical Genetics and Genomics (ACMG) criteria of PS2, PM1, PM2, PM5, PP4, PP3, and PS3. The p.Thr287lle can be classified as pathogenic or likely pathogenic from uncertain significance. Of the three mutations (p.Thr287lle, p.Gly281Glu and p.Pro285Thr), the conductance curves were similar, however, the p.Gly281Glu had worse conductance characters than the p.Thr287Ile and p.Pro285Thr when heteromerically transfected with KCNQ3 + KCNQ2 + mutations. That is, mimicking the genetic balance in human. The finding was also compatible with the amino acid weight changes in p.Gly281Glu. The p.Gly281Glu has more amino acid weight changes than p.Thr287lle and p.Pro285Thr (Table 3). The patient with p.Gly281Glu had worse clinical outcomes, including seizure frequencies and neurodevelopment, than patients with p.Thr287Ile and p.Pro285Thr. This finding increases our understanding of the association of KCNQ2 EE with seizures, poor neurodevelopmental outcomes, ASD, and dyskinetic movement disorder 
beyond neonatal age despite seizure remission, and it could supplement related knowledge and improve the management of affected patients' conditions.

The KCNQ2 mutation phenotype of "severe or EE" missense variants were clustered at S4, S5, the pore loop that contains the SF, S6, prehelix A, helix B, and the helix B-C linker of Kv7.2 [33]. Mutations in the SF might affect the channel-gating function and contribute to severe phenotypes. In our case, when p.Gly281Glu (patient 2) and p.Gly281Arg [52] were compared, the outcome of patients with p.Gly281Glu was more favorable than that of those with p.Gly281Arg in terms of phenotype and the functional current results related to HEK293 cells. KCNQ2 mutations affect the protein expression and M-current in the cells of the midbrain and striatum, and this is also a crucial factor in dyskinesia after the age of 4 weeks. In the patients presenting with EE, a transient signal change in the basal ganglia of the brain could be detected by an MRI in the neonatal period of approximately two-thirds of patients, but resolved at 2 to 4 years old [8]. More than $200 \mathrm{KCNQ} 2$ genotypes have been described thus far, but the phenotypes that persist after age 4 weeks are rarely reported. Neurodevelopmental outcomes such as cognition, language, life quality, and other reported behaviors should be further noted and managed by clinicians for the benefit of clinicians and parents.

Among the 35 mutations in the SF, the 5 that caused BFNCs were p.Asn258Ser, p.Asp259Thr, p.Asp259Tyr, p.Gly271Val and p.Tyr284Cys. Of those, 3 (60\%; p.Asn258Ser, p.Asp259Thr, and p.Tyr284Cys) exhibited a mutated amino acid that was lighter than that of the WT (Table 3). The p.Gly271Val and p.Asp259Tyr mutations exhibited increased the molecular weight of the new amino acid. An analysis of the pore diameters indicated relatively larger pores than in the others in the 5 mutations. Mutations that caused neonatal-onset EE represented the majority of mutations $(85.7 \%)$, and they exhibited larger mutated protein weights (Table 3) and a smaller pore diameter than those in mutations that caused BFNCs (Table 3). This finding indicates that a high mutated amino acid weight could be an obstacle to pore size, a phenomenon that may be critical for determining neurodevelopmental outcomes.

In neonatal-onset $K C N Q 2 \mathrm{EE}$, an MRI can reveal transient basal ganglion abnormalities. KCNQ2 exhibits immunoreactivity on the somata of dopaminergic and parvalbumin (PV)-positive (presumed GABAergic) cells of the substantia nigra, cholinergic large aspiny neurons of the striatum, and GABAergic and cholinergic neurons of the globus pallidus [15]. Thus, M-current dysfunction may contribute to the hyperactivity and network dysregulation characteristics of neonatal-onset EE, and $K C N Q 2 / 3$ channel regulation may be a target for therapeutic intervention [61]. However, reports of KCNQ2-associated movement disorder are rare. The selective openers of Kv7.2/3 channels might be candidates for the treatment of dyskinesias because antidyskinetic effects occurred at well-tolerated doses [62].

The most KCNQ2 mutation are missense mutations. Truncated and splice-site mutations are the next most common mutations. The phenotypes and genotypes are complex. In general, nonsense, splice, and frameshifts cause a mild phenotype of familial KCNQ2 BFNC. However, single mutations might manifest various clinical phenotypes within family members [63]. Changes in the functional current of the KCNQ2 mutants were not necessarily correlated to the phenotype. As these mutations were localized on the P loop, the selectivity of the channel to $\mathrm{K}+$ was reduced by variants, and channels became permeable to $\mathrm{Na}+$. This could ultimately explain why global currents were slightly affected. The loss of function is the major mechanism in KCNQ2 EE with de novo mutations. "Change of function" has been reported [64] recently in a KCNT2 de novo mutation causing EE. There is also an alternative mechanism, particularly for mutations located in the SF region. Patients with de novo mutations and $K C N Q 2 \mathrm{EE}$ are associated with severe developmental delays. KCNQ2 mutations found in the voltage sensor in S1-S4 or pore regions cause a more severe dominant-negative effect and lead to KCNQ2 EE. Mutations located in the calmodulin domain of the $\mathrm{C}$-terminal region were also reported to have more severe phenotypes. Some of the C-terminal mutations impair [65] surface expression by reducing protein stability or binding to calmodulin and thereby affecting transport to the surface membrane protein [28]. 
A study investigated a mutation (p.Lys526Asn in C-terminal), which caused the alteration of voltage-dependence of activation in these channels without changes in intracellular trafficking or plasma membrane expression [63]. The complex functions of the long C-terminal region exhibited interactions of syntaxin, phosphatidylinositol 4, 5-bisphosphate, ankyrinG, Syn-1A, and the A-kinase anchoring protein $[2,5,15-20,66]$. However, the pore domain in the KCNQ2 protein can affect channel gating and increase the threshold for channel activation without a significant channel number change $[13,28,63,65]$. The hypothesis is that mutations result in malfunctioning channels, and they do not affect the expression of cell KCNQ2 surface proteins.

This study has a few limitations. Due to the complexity of three dimensional graphics for the pore region, the predicted 3D model exhibited the pore region change by mutations. The determination of the phenotype is complex, and the phenotype may be due to the electrical charge of mutated proteins, the hydrophobic or hydrophilic characters of mutated proteins, modified genes, or acquired brain injury due to uncontrolled seizures. However, we found that the weight of mutated proteins can be a critical factor in mutations of the $K C N Q 2$ pore region. The predicted 3D structure denotes the effect of the mutation of the protein. Using HEK293 cells as a functional study in vitro with a potassium channel and the limitations of numbers of cells might contribute to the bias in currents, however, the numbers of cell are similar to other studies, which cause significant findings [52]. The nonexpression of potassium ion channels in HEK293 cells makes them an excellent model for whole-cell patch-clamp studies because only minor interfering currents occur. As a result, HEK293 cells have been widely used in cell biology, and the gene expression of HEK293 cells is similar to the gene expression of neurons.

\section{Conclusions}

These findings suggest that p.Thr287Ile, p.Pro285Thr. and p.Gly281Glu are pathogenic to KCNQ2 EE and cause homomeric and heteromeric Kv7.2 current changes. All mutations cause neonatal EE and ASD beyond neonatal age. In the SF mutations of KCNQ2, patient outcomes are correlated with amino acid weight changes in the KCNQ2 channel.

Supplementary Materials: The following are available online at https:/ www.mdpi.com/xxx/s1, Table S1: Currents and $\mathrm{V}_{1 / 2}$ in homomeric and heteromeric transfected HEK293 cell in the variants of p.Gly281Glu, p.Thr287Ile, and p.Gly281Glu. Figure S1: The total filters for the KCNQ2 protein expression on cell membranes are demonstrated and in the Figure 7A.

Author Contributions: I.-C.L. conceived the study and acted as the guarantors of the article. I.-C.L. and S.-H.W. collected and analyzed the data. S.-H.W. carried out the laboratory analysis. I.-C.L. drafted and revised the paper. J.-J.Y. revised the draft. Y.-M.L. prepared Figure 8. All authors have read and agreed to the published version of the manuscript.

Funding: This work was supported by Chung Shan Medical University and National Chung Hsing University grant NCHU-CSMU-11009 and Taiwan Ministry of Science and Technology MOST 110-2314-B-040-011-.

Institutional Review Board Statement: Ethical approval of the study was provided by the Chung Shan Medical University Hospital's Internal Review Board (IRB \#: CS2-14003).

Informed Consent Statement: Written informed consents were obtained from parents of patients.

Data Availability Statement: The datasets used and/or analyzed during the current study are available from the corresponding author on reasonable request.

Acknowledgments: We thank the Structural Bioinformatics Group, Imperial College, London for free use of Phyre2 and Horng-Huei Liou of the Department of Neurology, National Taiwan University Hospital, and everyone else who participated in the present project.

Conflicts of Interest: The authors declare no competing interest. 


\section{List of Abbreviations}

ACMG, American College of Medical Genetics and Genomics; ASD, autistic spectrum disorder; BFNCs, benign familial neonatal convulsions; DMEM, Dulbecco's modified Eagle's medium; EDTA, ethylenediaminetetraacetic acid; EE, epileptic encephalopathy; EEG, electroencephalogram; FBS, fetal bovine serum; HGMD, Human Gene Mutation Database; K, slope; MRI, magnetic resonance image; NCBI, National Center for Biotechnology Information; PMSF, phenylmethyl sulfonyl fluoride; PV, parvalbumin; PVDF, polyvinylidene difluoride; OR, odds ratio; OXC, oxcarbazepine; SF, selectivity filter; $\mathrm{V}_{1 / 2}$, half-activation potential; WT, wild type.

\section{References}

1. Leppert, M.; Anderson, V.E.; Quattlebaum, T.; Stauffer, D.; O'Connell, P.; Nakamura, Y.; White, R. Benign familial neonatal convulsions linked to genetic markers on chromosome 20. Nature 1989, 337, 647-648. [CrossRef] [PubMed]

2. Biervert, C.; Schroeder, B.C.; Kubisch, C.; Berkovic, S.F.; Propping, P.; Jentsch, T.J.; Steinlein, O.K. A potassium channel mutation in neonatal human epilepsy. Science 1998, 279, 403-406. [CrossRef]

3. Singh, N.A.; Charlier, C.; Stauffer, D.; DuPont, B.R.; Leach, R.J.; Melis, R.; Leppert, M. A novel potassium channel gene, KCNQ2, is mutated in an inherited epilepsy of newborns. Nat. Genet. 1998, 18, 25-29. [CrossRef] [PubMed]

4. Wang, H.S.; Pan, Z.; Shi, W.; Brown, B.S.; Wymore, R.S.; Cohen, I.S.; McKinnon, D. KCNQ2 and KCNQ3 potassium channel subunits: Molecular correlates of the M-channel. Science 1998, 282, 1890-1893. [CrossRef] [PubMed]

5. Lerche, H.; Biervert, C.; Alekov, A.K.; Schleithoff, L.; Lindner, M.; Klinger, W.; Steinlein, O.K. A reduced K+ current due to a novel mutation in KCNQ2 causes neonatal convulsions. Ann. Neurol. 1999, 46, 305-312. [CrossRef]

6. Kato, M.; Yamagata, T.; Kubota, M.; Arai, H.; Yamashita, S.; Nakagawa, T.; Saitsu, H. Clinical spectrum of early onset epileptic encephalopathies caused by KCNQ2 mutation. Epilepsia 2013, 54, 1282-1287. [CrossRef] [PubMed]

7. Weckhuysen, S.; Mandelstam, S.; Suls, A.; Audenaert, D.; Deconinck, T.; Claes, L.R.; de Jonghe, P. KCNQ2 encephalopathy: Emerging phenotype of a neonatal epileptic encephalopathy. Ann. Neurol. 2012, 71, 15-25. [CrossRef]

8. Weckhuysen, S.; Ivanovic, V.; Hendrickx, R.; Van Coster, R.; Hjalgrim, H.; Moller, R.S.; De Jonghe, P. Extending the KCNQ2 encephalopathy spectrum: Clinical and neuroimaging findings in 17 patients. Neurology 2013, 81, 1697-1703. [CrossRef]

9. Choi, S.J.; Mukai, J.; Kvajo, M.; Xu, B.; Diamantopoulou, A.; Pitychoutis, P.M.; Zhang, H. A Schizophrenia-Related Deletion Leads to KCNQ2-Dependent Abnormal Dopaminergic Modulation of Prefrontal Cortical Interneuron Activity. Cereb. Cortex 2018, 28, 2175-2191. [CrossRef]

10. Jiang, Y.H.; Yuen, R.K.; Jin, X.; Wang, M.; Chen, N.; Wu, X.; Scherer, S.W. Detection of clinically relevant genetic variants in autism spectrum disorder by whole-genome sequencing. Am. J. Hum. Genet. 2013, 93, 249-263. [CrossRef]

11. Vilan, A.; Mendes Ribeiro, J.; Striano, P.; Weckhuysen, S.; Weeke, L.C.; Brilstra, E.; Cilio, M.R. A Distinctive Ictal AmplitudeIntegrated Electroencephalography Pattern in Newborns with Neonatal Epilepsy Associated with KCNQ2 Mutations. Neonatology 2017, 112, 387-393. [CrossRef]

12. Chen, D.Y.; Chowdhury, S.; Farnaes, L.; Friedman, J.R.; Honold, J.; Dimmock, D.P.; Gold, O. Rapid Diagnosis of KCNQ2Associated Early Infantile Epileptic Encephalopathy Improved Outcome. Pediatr. Neurol. 2018, 86, 69-70. [CrossRef]

13. Lee, I.C.; Yang, J.J.; Wong, S.H.; Liou, Y.M.; Li, S.Y. Heteromeric Kv7.2 current changes caused by loss-of-function of KCNQ2 mutations are correlated with long-term neurodevelopmental outcomes. Sci. Rep. 2020, 10, 13375. [CrossRef] [PubMed]

14. Miceli, F.; Soldovieri, M.V.; Ambrosino, P.; Barrese, V.; Migliore, M.; Cilio, M.R.; Taglialatela, M. Genotype-phenotype correlations in neonatal epilepsies caused by mutations in the voltage sensor of K(v)7.2 potassium channel subunits. Proc. Natl. Acad. Sci. USA 2013, 110, 4386-4391. [CrossRef]

15. Cooper, E.C.; Harrington, E.; Jan, Y.N.; Jan, L.Y. M channel KCNQ2 subunits are localized to key sites for control of neuronal network oscillations and synchronization in mouse brain. J. Neurosci. 2001, 21, 9529-9540. [CrossRef] [PubMed]

16. Devaux, J.; Dhifallah, S.; De Maria, M.; Stuart-Lopez, G.; Becq, H.; Milh, M.; Aniksztejn, L. A possible link between KCNQ2and STXBP1-related encephalopathies: STXBP1 reduces the inhibitory impact of syntaxin-1A on M current. Epilepsia 2017, 58, 2073-2084. [CrossRef] [PubMed]

17. Soldovieri, M.V.; Ambrosino, P.; Mosca, I.; De Maria, M.; Moretto, E.; Miceli, F.; Taglialatela, M. Early-onset epileptic encephalopathy caused by a reduced sensitivity of Kv7.2 potassium channels to phosphatidylinositol 4,5-bisphosphate. Sci. Rep. 2016, 6, 38167. [CrossRef] [PubMed]

18. Xu, M.; Cooper, E.C. An Ankyrin-G N-terminal Gate and Protein Kinase CK2 Dually Regulate Binding of Voltage-gated Sodium and KCNQ2/3 Potassium Channels. J. Biol. Chem. 2015, 290, 16619-16632. [CrossRef]

19. Zaydman, M.A.; Cui, J. PIP2 regulation of KCNQ channels: Biophysical and molecular mechanisms for lipid modulation of voltage-dependent gating. Front. Physiol. 2014, 5, 195. [CrossRef]

20. Zhang, H.; Craciun, L.C.; Mirshahi, T.; Rohács, T.; Lopes, C.M.; Jin, T.; Logothetis, D.E. PIP(2) activates KCNQ channels, and its hydrolysis underlies receptor-mediated inhibition of M currents. Neuron 2003, 37, 963-975. [CrossRef] 
21. Ambrosino, P.; Alaimo, A.; Bartollino, S.; Manocchio, L.; De Maria, M.; Mosca, I.; Soldovieri, M.V. Epilepsy-causing mutations in Kv7.2 C-terminus affect binding and functional modulation by calmodulin. Biochim. Biophys. Acta 2015, 1852, 1856-1866. [CrossRef] [PubMed]

22. Choveau, F.S.; Shapiro, M.S. Regions of KCNQ K(+) channels controlling functional expression. Front. Physiol 2012, 3 , 397. [CrossRef] [PubMed]

23. Zhou, X.; Zhuang, F.; Li, H.; Zheng, K.; Hong, Z.; Feng, W.; Chen, J. Calmodulin regulates KCNQ2 function in epilepsy. Am. J. Transl. Res. 2016, 8, 5610-5618. [PubMed]

24. Wang, J.J.; Li, Y. KCNQ potassium channels in sensory system and neural circuits. Acta Pharmacol. Sin. 2016, 37, 25-33. [CrossRef]

25. Miceli, F.; Soldovieri, M.V.; Ambrosino, P.; De Maria, M.; Migliore, M.; Migliore, R.; Taglialatela, M. Early-onset epileptic encephalopathy caused by gain-of-function mutations in the voltage sensor of Kv7.2 and Kv7.3 potassium channel subunits. J. Neurosci. 2015, 35, 3782-3793. [CrossRef]

26. Maljevic, S.; Naros, G.; Yalcin, O.; Blazevic, D.; Loeffler, H.; Caglayan, H.; Lerche, H. Temperature and pharmacological rescue of a folding-defective, dominant-negative KV 7.2 mutation associated with neonatal seizures. Hum. Mutat. 2011, 32, E2283-E2293. [CrossRef]

27. Wuttke, T.V.; Penzien, J.; Fauler, M.; Seebohm, G.; Lehmann-Horn, F.; Lerche, H.; Jurkat-Rott, K. Neutralization of a negative charge in the S1-S2 region of the KV7.2 (KCNQ2) channel affects voltage-dependent activation in neonatal epilepsy. J. Physiol. 2008, 586, 545-555. [CrossRef]

28. Orhan, G.; Bock, M.; Schepers, D.; Ilina, E.I.; Reichel, S.N.; Löffler, H.; Maljevic, S. Dominant-negative effects of KCNQ2 mutations are associated with epileptic encephalopathy. Ann. Neurol. 2014, 75, 382-394. [CrossRef]

29. Millichap, J.J.; Miceli, F.; De Maria, M.; Keator, C.; Joshi, N.; Tran, B.; Taglialatela, M. Infantile spasms and encephalopathy without preceding neonatal seizures caused by KCNQ2 R198Q, a gain-of-function variant. Epilepsia 2017, 58, e10-e15. [CrossRef]

30. Devaux, J.; Abidi, A.; Roubertie, A.; Molinari, F.; Becq, H.; Lacoste, C.; Aniksztejn, L. A Kv7.2 mutation associated with early onset epileptic encephalopathy with suppression-burst enhances Kv7/M channel activity. Epilepsia 2016, 57, e87-e93. [CrossRef]

31. Sands, T.T.; Miceli, F.; Lesca, G.; Beck, A.E.; Sadleir, L.G.; Arrington, D.K.; Cilio, M.R. Autism and developmental disability caused by KCNQ3 gain-of-function variants. Ann. Neurol. 2019, 86, 181-192. [CrossRef] [PubMed]

32. Abidi, A.; Devaux, J.J.; Molinari, F.; Alcaraz, G.; Michon, F.X.; Sutera-Sardo, J.; Aniksztejn, L. A recurrent KCNQ2 pore mutation causing early onset epileptic encephalopathy has a moderate effect on M current but alters subcellular localization of Kv7 channels. Neurobiol. Dis. 2015, 80, 80-92. [CrossRef] [PubMed]

33. Zhang, J.; Kim, E.C.; Chen, C.; Procko, E.; Pant, S.; Lam, K.; Chung, H.J. Identifying mutation hotspots reveals pathogenetic mechanisms of KCNQ2 epileptic encephalopathy. Sci. Rep. 2020, 10, 4756. [CrossRef] [PubMed]

34. Baculis, B.C.; Zhang, J.; Chung, H.J. The Role of K(v)7 Channels in Neural Plasticity and Behavior. Front. Physiol. 2020, 11, 568667. [CrossRef]

35. Brown, D.A.; Passmore, G.M. Neural KCNQ (Kv7) channels. Br. J. Pharmacol. 2009, 156, 1185-1195. [CrossRef]

36. Sun, J.; MacKinnon, R. Cryo-EM Structure of a KCNQ1/CaM Complex Reveals Insights into Congenital Long QT Syndrome. Cell 2017, 169, 1042-1050.e1049. [CrossRef]

37. Cui, J. Voltage-Dependent Gating: Novel Insights from KCNQ1 Channels. Biophys. J. 2016, 110, 14-25. [CrossRef]

38. Dhamija, R.; Goodkin, H.P.; Bailey, R.; Chambers, C.; Brenton, J.N. A Case of KCNQ2-Associated Movement Disorder Triggered by Fever. J. Child Neurol. 2017, 32, 1123-1124. [CrossRef]

39. Blumkin, L.; Suls, A.; Deconinck, T.; De Jonghe, P.; Linder, I.; Kivity, S.; Lerman-Sagie, T. Neonatal seizures associated with a severe neonatal myoclonus like dyskinesia due to a familial KCNQ2 gene mutation. Eur. J. Paediatr. Neurol. 2012, 16, 356-360. [CrossRef]

40. Kelley, L.A.; Mezulis, S.; Yates, C.M.; Wass, M.N.; Sternberg, M.J. The Phyre2 web portal for protein modeling, prediction and analysis. Nat. Protoc. 2015, 10, 845-858. [CrossRef]

41. Volkers, L.; Rook, M.B.; Das, J.H.; Verbeek, N.E.; Groenewegen, W.A.; van Kempen, M.J.; Koeleman, B.P. Functional analysis of novel KCNQ2 mutations found in patients with Benign Familial Neonatal Convulsions. Neurosci. Lett. 2009, 462, 24-29. [CrossRef] [PubMed]

42. Selyanko, A.A.; Hadley, J.K.; Brown, D.A. Properties of single M-type KCNQ2/KCNQ3 potassium channels expressed in mammalian cells. J. Physiol. 2001, 534 Pt 1, 15-24. [CrossRef] [PubMed]

43. Stefani, E.; Toro, L.; Perozo, E.; Bezanilla, F. Gating of Shaker K+ channels: I. Ionic and gating currents. Biophys. J. 1994, 66, 996-1010. [CrossRef]

44. Milh, M.; Lacoste, C.; Cacciagli, P.; Abidi, A.; Sutera-Sardo, J.; Tzelepis, I.; Villard, L. Variable clinical expression in patients with mosaicism for KCNQ2 mutations. Am. J. Med. Genet. A 2015, 167, 2314-2318. [CrossRef] [PubMed]

45. Yalçin, O.; Cağlayan, S.H.; Saltik, S.; Cokar, O.; Ağan, K.; Dervent, A.; Steinlein, O.K. A novel missense mutation (N258S) in the KCNQ2 gene in a Turkish family afflicted with benign familial neonatal convulsions (BFNC). Turk. J. Pediatr. 2007, 49, 385-389.

46. Hortigüela, M.; Fernández-Marmiesse, A.; Cantarín, V.; Gouveia, S.; García-Peñas, J.J.; Fons, C.; Gutiérrez-Solana, L.G. Clinical and genetic features of 13 Spanish patients with KCNQ2 mutations. J. Hum. Genet. 2017, 62, 185-189. [CrossRef] [PubMed]

47. Stenson, P.D.; Mort, M.; Ball, E.V.; Shaw, K.; Phillips, A.; Cooper, D.N. The Human Gene Mutation Database: Building a comprehensive mutation repository for clinical and molecular genetics, diagnostic testing and personalized genomic medicine. Hum. Genet. 2014, 133, 1-9. [CrossRef] 
48. Saitsu, H.; Kato, M.; Koide, A.; Goto, T.; Fujita, T.; Nishiyama, K.; Matsumoto, N. Whole exome sequencing identifies KCNQ2 mutations in Ohtahara syndrome. Ann. Neurol. 2012, 72, 298-300. [CrossRef]

49. Milh, M.; Boutry-Kryza, N.; Sutera-Sardo, J.; Mignot, C.; Auvin, S.; Lacoste, C.; Villard, L. Similar early characteristics but variable neurological outcome of patients with a de novo mutation of KCNQ2. Orphanet J. Rare Dis. 2013, 8, 80. [CrossRef]

50. Pisano, T.; Numis, A.L.; Heavin, S.B.; Weckhuysen, S.; Angriman, M.; Suls, A.; Cilio, M.R. Early and effective treatment of KCNQ2 encephalopathy. Epilepsia 2015, 56, 685-691. [CrossRef]

51. Millichap, J.J.; Park, K.L.; Tsuchida, T.; Ben-Zeev, B.; Carmant, L.; Flamini, R.; Cooper, E.C. KCNQ2 encephalopathy: Features, mutational hot spots, and ezogabine treatment of 11 patients. Neurol. Genet. 2016, 2, e96. [CrossRef] [PubMed]

52. Gomis-Perez, C.; Urrutia, J.; Marce-Grau, A.; Malo, C.; Lopez-Laso, E.; Felipe-Rucian, A.; Villarroel, A. Homomeric Kv7.2 current suppression is a common feature in KCNQ2 epileptic encephalopathy. Epilepsia 2019, 60, 139-148. [CrossRef] [PubMed]

53. Zhou, X.; Ma, A.; Liu, X.; Huang, C.; Zhang, Y.; Shi, R.; Li, S. Infantile seizures and other epileptic phenotypes in a Chinese family with a missense mutation of KCNQ2. Eur. J. Pediatr. 2006, 165, 691-695. [CrossRef] [PubMed]

54. Martin, H.C.; Kim, G.E.; Pagnamenta, A.T.; Murakami, Y.; Carvill, G.L.; Meyer, E.; Taylor, J.C. Clinical whole-genome sequencing in severe early-onset epilepsy reveals new genes and improves molecular diagnosis. Hum. Mol. Genet. 2014, 23, 3200-3211. [CrossRef] [PubMed]

55. Zhang, F.; Cheng, Y.; Li, H.; Jia, Q.; Zhang, H.; Zhao, S. Inhibition of Kv7/M Channel Currents by the Local Anesthetic Chloroprocaine. Pharmacology 2015, 96, 124-130. [CrossRef] [PubMed]

56. Yalcıntepe, S.; Ozguc Comlek, F.; Gurkan, H.; Demir, S.; Atlı, E.I.; Atlı, E.; Tutunculer Kokenli, F. The Application of Next Generation Sequencing Maturity Onset Diabetes of the Young Gene Panel in Turkish Patients from Trakya Region. J. Clin. Res. Pediatr. Endocrinol. 2021, 13, 320-331. [CrossRef] [PubMed]

57. Laccetta, G.; Fiori, S.; Giampietri, M.; Ferrari, A.; Cetica, V.; Bernardini, M.; Ghirri, P. A de novo KCNQ2 Gene Mutation Associated With Non-familial Early Onset Seizures: Case Report and Revision of Literature Data. Front. Pediatr. 2019, 7, 348. [CrossRef]

58. Schneider, A.L.; Myers, C.T.; Muir, A.M.; Calvert, S.; Basinger, A.; Perry, M.S.; Scheffer, I.E. FBXO28 causes developmental and epileptic encephalopathy with profound intellectual disability. Epilepsia 2021, 62, e13-e21. [CrossRef]

59. Parrini, E.; Marini, C.; Mei, D.; Galuppi, A.; Cellini, E.; Pucatti, D.; Guerrini, R. Diagnostic Targeted Resequencing in 349 Patients with Drug-Resistant Pediatric Epilepsies Identifies Causative Mutations in 30 Different Genes. Hum. Mutat. 2017, 38, 216-225. [CrossRef]

60. Zhang, Q.; Li, J.; Zhao, Y.; Bao, X.; Wei, L.; Wang, J. Gene mutation analysis of 175 Chinese patients with early-onset epileptic encephalopathy. Clin. Genet. 2017, 91, 717-724. [CrossRef]

61. Cao, Y.; Bartolomé-Martín, D.; Rotem, N.; Rozas, C.; Dellal, S.S.; Chacon, M.A.; Faber, D.S. Rescue of homeostatic regulation of striatal excitability and locomotor activity in a mouse mode'l of Huntingtons disease. Proc. Natl. Acad. Sci. USA 2015, 112, 2239-2244. [CrossRef]

62. Sander, S.E.; Lambrecht, C.; Richter, A. The K(V)7.2/3 preferring channel opener ICA 27243 attenuates L-DOPA-induced dyskinesia in hemiparkinsonian rats. Neurosci. Lett. 2013, 545, 59-63. [CrossRef] [PubMed]

63. Borgatti, R.; Zucca, C.; Cavallini, A.; Ferrario, M.; Panzeri, C.; Castaldo, P.; Bassi, M.T. A novel mutation in KCNQ2 associated with BFNC, drug resistant epilepsy, and mental retardation. Neurology 2004, 63, 57-65. [CrossRef] [PubMed]

64. Gururaj, X.; Palmer, E.E.; Sheehan, G.D.; Kandula, T.; Macintosh, R.; Bhattacharjee, A. A De Novo Mutation in the SodiumActivated Potassium Channel KCNT2 Alters Ion Selectivity and Causes Epileptic Encephalopathy. Cell. Rep. 2017, 21, 926-933. [CrossRef] [PubMed]

65. Maljevic, S.; Wuttke, T.V.; Lerche, H. Nervous system KV7 disorders: Breakdown of a subthreshold brake. J. Physiol. 2008, 586, 1791-1801. [CrossRef] [PubMed]

66. Lee, I.C.; Chang, M.Y.; Liang, J.S.; Chang, T.M. Ictal and interictal electroencephalographic findings can contribute to early diagnosis and prompt treatment in KCNQ2-associated epileptic encephalopathy. J. Formos. Med. Assoc. 2021, 120 Pt 3, 744-754. [CrossRef] 